\title{
Evaluation of under- and overreporting of energy intake in the 24-hour diet recalls in the European Prospective Investigation into Cancer and Nutrition (EPIC)
}

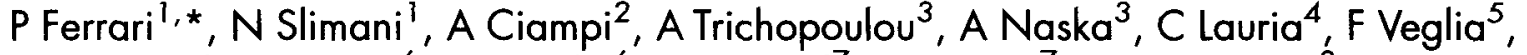

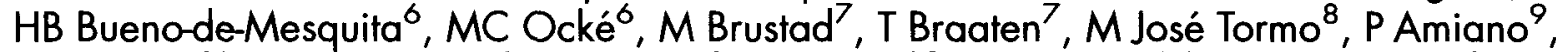 \\ I Mattisson ${ }^{10}, \mathrm{G}$ Johansson ${ }^{11}$, A Welch ${ }^{12}, \mathrm{G} \mathrm{Davey}^{13}, \mathrm{~K}$ Overvad $^{14}$, A Tiønneland ${ }^{15}$, \\ F Clavel-Chapelon $^{16}, \mathrm{~A} \mathrm{Thiebaut}^{16}$, J Linseisen ${ }^{17}, \mathrm{H}^{\text {Boeing }}{ }^{18}, \mathrm{~B} \mathrm{Hemon}^{1}$ and $\mathrm{E} \mathrm{Riboli}{ }^{1}$ \\ 'Unit of Nutrition and Cancer, International Agency for Research on Cancer, 150 cours Albert-Thomas, 69372 lyon \\ Cedex 08, France: ${ }^{2}$ Department of Epidemiology and Biostatistics, McGill University, Montreal, Quebec, Canada: \\ ${ }^{3}$ Department of Hygiene and Epidemiology, School of Medicine, University of Athens, Greece: ${ }^{4}$ Cancer Registry, \\ 'Civile - M.P. Arezzo' Hosptial, Ragusa, Italy: Institute for Scientific Interchange Foundation, Turin, Italy: ${ }^{6} \mathrm{Centre}$ of \\ Nutrition and Health, National Institute for Public Health and the Environment, Bilthoven, The Netherlands: ${ }^{7}$ Institule \\ of Community Medicine, University of Tromsø, Norway: ${ }^{8}$ Department of Epidemiology, Regional Council of Health

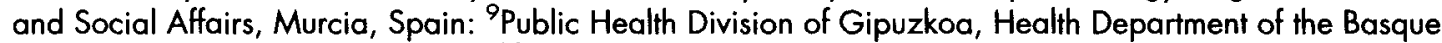 \\ Government, San Sebastian, Spain: ${ }^{10}$ Department of Medicine, Surgery and Orthopaedics, Lund University, Malmö, \\ Sweden: "Department of Nurritional Research, University of Umeá, Sweden: ${ }^{12}$ Institute of Public Health, School of \\ Clinical Medicine, University of Cambridge, UK: ${ }^{13}$ Cancer Research UK, Epidemiology Unit, University of Oxford, \\ UK: ${ }^{14}$ Department of Epidemiology and Social Medicine, University of Aarhus, Denmark: ${ }^{15}$ Department of Cancer \\ Epidemiology, Danish Cancer Society, Copenhagen, Denmark: ${ }^{16}$ INSERM, U521, Institute Gustave Roussy, Villejuif, \\ France: ${ }^{17}$ Division of Clinical Epidemiology, German Cancer Research Centre, Heidelberg, Germany: ${ }^{8}$ German \\ Institute of Human Nutrition, Potsdam-Rehbrücke, Germany
}

\begin{abstract}
Objective: To evaluate under- and overreporting and their determinants in the EPIC 24-hour diet recall (24-HDR) measurements collected in the European Prospective Investigation into Cancer and Nutrition (EPIC).

Design: Cross-sectional analysis. 24-HDR measurements were obtained by means of a standardised computerised interview program (EPIC-SOFT). The ratio of reported energy intake (EI) to estimated basal metabolic rate (BMR) was used to ascertain the magnitude, impact and determinants of misreporting. Goldberg's cut-off points were used to identify participants with physiologically extreme low or high energy intake. At the aggregate level the value of 1.55 for physical activity level (PAL) was chosen as reference. At the individual level we used multivariate statistical techniques to identify factors that could explain EI/BMR variability. Analyses were performed by adjusting for weight, height, age at recall, special diet, smoking status, day of recall (weekday vs. weekend day) and physical activity.

Setting: Twenty-seven redefined centres in the 10 countries participating in the EPIC project.

Subjects: In total, 35955 men and women, aged 35-74 years, participating in the nested EPIC calibration sub-studies.

Results: While overreporting has only a minor impact, the percentage of subjects identified as extreme underreporters was $13.8 \%$ and $10.3 \%$ in women and men, respectively. Mean EI/BMR values in men and women were 1.44 and 1.36 including all subjects, and 1.50 and 1.44 after exclusion of misreporters. After exclusion of misreporters, adjusted EI/BMR means were consistently less than $10 \%$ different from the expected value of 1.55 for PAL (except for women in Greece and in the UK), with overall differences equal to $4.0 \%$ and $7.4 \%$ for men and women, respectively. We modelled the probability of being an underreporter in association with several individual characteristics. After adjustment for age, height, special diet, smoking status, day of recall and physical activity at work, logistic regression analyses resulted in an odds ratio (OR) of being an underreporter for the highest vs. the lowest quartile of body mass index (BMI) of 3.52 (95\% confidence interval (CI) $2.91-4.26)$ in men and 4.80 (95\% CI 4.115.61) in women, indicating that overweight subjects are significantly more likely to underestimate energy intake than subjects in the bottom BMI category. Older people
\end{abstract}


were less likely to underestimate energy intake: ORs were 0.58 (95\% CI $0.45-0.77)$ and $0.74(95 \% \mathrm{CI} 0.63-0.88)$ for age $(\geq 65$ years vs. $<50$ years). Special diet and day of the week showed strong effects.

Conclusion: EI tends to be underestimated in the vast majority of the EPIC centres, although to varying degrees; at the aggregate level most centres were below the expected reference value of 1.55 . Underreporting seems to be more prevalent among women than men in the EPIC calibration sample. The hypothesis that BMI (or weight) and age are causally related to underreporting seems to be confirmed in the present work. This introduces further complexity in the within-group (centre or country) and between-group calibration of dietary questionnaire measurements to deattenuate the diet-disease relationship.

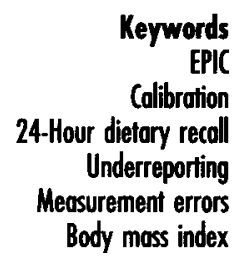

In epidemiological studies aimed at investigating the relationship between diet and diseases of interest, the measures of association may be attenuated due to measurement error when estimating individual exposure. One way to overcome this loss of power is, among others, to increase the heterogeneity of the dietary exposure, thus reducing the impact of measurement error. In epidemiological studies this can be achieved by considering populations with very different dietary habits. This was the rationale for setting up the European Prospective Investigation into Cancer and Nutrition (EPIC) ${ }^{\mathbf{1}}$, a multicentre cohort study on diet and cancer conducted in 23 administrative centres in 10 European countries. This study design allows the diet-cancer relationship to be investigated at the individual level, within each of the separate cohorts, and at the ecological level, through the comparison of cancer incidence and dietary habits among cohorts.

In EPIC, individual habitual dietary intake was assessed by means of different validated questionnaires developed and administered independently in each country ${ }^{2}$. Different methods were chosen because the cohorts started and developed separately. Moreover, it was difficult to use the same dietary assessment instrument to capture the large heterogeneity in dietary patterns existing across centres. Semi-quantitative food-frequency questionnaires, modified dietary history questionnaires or combined methods ${ }^{2}$ were used to assess usual dietary intakes. Dietary assessment methods are, however, very likely to be affected by random and systematic withinperson measurement errors which, in addition, may vary in magnitude and direction depending on the dietary method used ${ }^{3}$. Statistical methods have therefore been proposed to take into account the impact of measurement errors and obtain correct estimates of dietary exposure and cancer incidence associations.

Rosner et al. ${ }^{4}$ proposed a calibration method to correct for random and systematic error in baseline dietary assessment measurements using a more accurate method as reference (so-called 'reference measurement'). The statistical method requires that, on a sub-sample of the study participants, a second dietary reference measurement is taken in order to estimate the attenuation coefficient, the parameter that will adjust the observed (naive) diet-cancer relationship. Within the EPIC study framework it was decided to use 24-hour dietary recalls (24-HDRs) to provide reference measurements. A single 24-HDR was collected from a sample of 36900 participants from the entire EPIC cohort in order to express individual dietary intakes according to the same reference scale and to adjust observed diet-disease associations for attenuation.

The calibration approach requires first that the 24-HDR measurements provide unbiased estimates at the population level. This statistical requirement is, however, difficult to satisfy in practice. Indeed, it has been extensively recognised that all self-reported dietary intakes contain measurement errors ${ }^{5,6}$. However, if the direction and magnitude of systematic dietary measurement errors are approximately constant across study populations, the reference method can be used for withinand between-cohort calibration. The questionnaires are therefore calibrated against a dietary method with only a relative validity, but which is comparable across study populations ${ }^{7}$. In order to satisfy this objective, the 24-HDR interview procedure was highly standardised across EPIC centres, using an ad boc computerised program (EPICSOFT) ${ }^{8}$.

In the present paper we set out first to evaluate underand overreporting in 24-HDRs and to provide a comparison of their magnitude across the EPIC centres, in order to gain a better insight into the effect of standardisation of the 24-hour diet recall measurement across study populations. In the absence of perfect reference measurements such as urinary nitrogen or doubly labelled water measurements ${ }^{9}$, which are too expensive to use in large epidemiological studies, we used the computed ratio of total energy intake to predicted basal metabolic rate (EI/BMR), as proposed by Goldberg et al. $^{10}$ and Black ${ }^{11}$, as an empirical approach to evaluate the (relative) validity of reported total energy intakes. Furthermore, we investigated the relationship between extreme under- and overreporting observed in the 24HDRs and their potentially associated factors, using the specific EI/BMR cut-off proposed by Goldberg et al. ${ }^{10}$

Another important statistical requirement for calibrating 
dietary measurements is that the correlation between 24 HDR and dietary questionnaire (DQ) errors be independent. However, this issue is beyond the scope of the present work and will not be addressed in this paper.

\section{Material and methods}

The EPIC study population includes over 500000 participants from 10 countries who completed a baseline dietary and other lifestyle questionnaires ${ }^{2}$. The study participants were either population-based (Bilthoven in The Netherlands, Greece, Spain, Germany, Sweden, Denmark, Norway, Italy, Cambridge and a small part of the Oxford cohort from the UK), participants in breast cancer screening (Utrecht in The Netherlands, Florence in Italy), or teachers and school workers in France. In Oxford, most of the cohort was recruited among subjects with an interest in health and/or vegetarian eating habits. Blood donors were also recruited in different proportions in certain Italian and Spanish centres. In France, Norway, Utrecht (The Netherlands) and Naples (Italy) only women were recruited.

A sub-sample of 36900 participants gave a single 24hour dietary recall interview to use as the reference calibration method. The calibration sample was randomly chosen from each cohort, weighted according to the cumulative number of cancer cases expected over 10 years of follow-up by gender and 5-year age strata. Around 4000 24-HDRs were recommended per country, according to calculations detailed elsewhere ${ }^{12}$, in order to provide a large sample from each participating cohort. The initial 23 EPIC co-ordinating centres were redefined in France, the UK and Norway. In the UK, the 'health-conscious' group and the subjects recruited from the general population both in Cambridge and Oxford (general population group) were considered separately. In France and Norway, where the study participants were scattered all over the country, the groups were sub-divided into, respectively, four and two geographical regions. Finally 27 centres were considered in the present analysis. Details of the EPIC calibration study design, sampling procedures and population characteristics are described elsewhere in this supplement ${ }^{13}$. The sampling procedures were designed in order to obtain a homogeneous distribution by season and day of interview to control for possible dayto-day and seasonal variations in dietary intakes. A single 24-HDR was collected from a stratified random sample using an ad boc software (EPIC-SOFT), specifically designed to standardise dietary measurements and control the overall interview procedures across heterogeneous study populations ${ }^{8}$. In the absence of a standardised European nutrient database, which is still being developed $^{14}$, country-specific food composition tables were used to calculate nutrient intakes. A recent review of the national food composition tables available in countries participating in EPIC ${ }^{15}$ suggested that energy measurements are reasonably comparable between countries.

In order to evaluate the (relative) 'validity' and to assess comparability of dietary measurements among EPIC cohorts in the 24-HDR data, we focused on self-reported energy intake values. A fundamental physiological principle of energy metabolism is that energy intake equals energy expenditure if body weight is stable. Recent sophisticated (and expensive) techniques to estimate energy expenditure, such as doubly labelled water, would have made it possible to validate reported energy intake. However, this method is too costly to be applied routinely in epidemiological studies, and alternative ways to evaluate reported energy intake are necessary. The ratio of energy intake (EI) over estimated basal metabolic rate (BMR), taking age, sex, weight and height into account, can be used as an internal validation of reported energy intake ${ }^{16}$. Energy expenditure (EE) over BMR is also known as physical activity level (PAL). The (relative) validity of reported energy intake was assessed by assuming the fundamental equation $\mathrm{EI}=\mathrm{EE}$. The reported EI may be expressed as EI/BMR and compared with a reference PAL in a given population. The confidence limits of agreement between EI/BMR and PAL can be determined by considering physiological variations in both BMR and PAL, daily variations in energy intake and the number of repeated measurements per individual. Goldberg et al ${ }^{10}$ and more recently $\mathrm{Black}^{11}$ constructed tables for lower and upper limits of EI/BMR values based on Food and Agriculture Organization/World Health Organization energy requirement estimates and energy expenditures from studies using doubly labelled water measurements ${ }^{6}$ The limits were calculated assuming that the value of PAL equals 1.55 . These limits represent the values below or above which it is statistically unlikely that the reported intake represents habitual intake or a low or high intake obtained by chance. Using the EI/BMR cut-off points proposed by Goldberg and Black ${ }^{10,11}$ on the basis of intraindividual variations, it is possible to determine whether the mean reported energy intake is a plausible measure at the aggregate (i.e. population) level, and to identify, at the individual level, study participants out of range of physiologically plausible energy intake values. The choice of 1.55 for PAL is motivated by the fact that the EPIC calibration sample was mainly composed of middle-aged study participants ${ }^{13}$ with overall moderate physical activity $^{17}$. To calculate the limits of acceptance for EI/BMR, we considered $23 \%$ of within-subject variation for energy, $15 \%$ of between-subject variation for PAL and $8.5 \%$ of within-subject variation for estimated BMR, according to the recent work by Black ${ }^{11}$. Limits were computed according to a $95 \%$ confidence interval (CI).

For an evaluation of EI/BMR at the aggregate level, according to the formula in Goldberg et al.'s paper ${ }^{10}$, it was possible to identify the lower confidence limit, given the number of days of diet assessment and the sample size 
in the different EPIC centres. Centre- and gender- specific lower limits were therefore considered. Since analyses at the individual level suggested that overreporting was marginal in the EPIC 24-HDR, evaluation of misreporting at the aggregate level focused only on underreporting. As pointed out by Black ${ }^{11}$, at the aggregate level, with one dietary measurement per individual and when the sample size $(n)$ is greater than 100 , as is the case in the EPIC centres, the number of subjects does not alter Goldberg's cut-off substantially (i.e. it is of little importance to determine the ability to detect bias in the mean intake).

At the individual level $(n=1)$, the intra-individual variability values used in the formula proposed by Goldberg resulted in lower and upper limits equal to 0.88 and 2.72 , respectively. Participants with calculated values of EI/BMR lower than 0.88 were therefore considered 'extreme underreporters', and participants with values above 2.72 were considered 'extreme overreporters'. The empirical approach used at the individual level does not identify all under- or overreporters but only those who, under different assumptions, should be considered as physiologically implausible.
Black $^{18}$ discusses extensively the sensitivity and the specificity of such limits to identify underreporters in a study population. We refer the reader to a later section of that paper for a more complete discussion about this.

\section{Statistical analysis}

Chi-square test statistics were used to test the homogeneity of distributions of mis-, under- and overreporting within countries and across centres. Centre- and country-specific crude and adjusted mean values were calculated for EI/BMR and energy intake before and after exclusion of subjects whose EI/BMR values were below 0.88 and above 2.72. A weighted analysis of covariance model was used to adjust for body mass index (BMI), height and age at recall (continuous variables), with weights calculated to take into account day of recall (weekday vs. weekend day) and physical activity (PA) at work (categorical variables). This procedure was used to relax the assumption of parallelism for adjusting factors across centres. These variables were chosen because they have been found to explain statistically EI/BMR and energy intake variability in the EPIC data

Table 1 Sample size and percentage of misreporters (Mis-R), underreporters (Under-R) and overreporters (Over-R) in the European Prospective Investigation into Cancer and Nutrition (EPIC) 24-hour dietary recalls, among men and women

\begin{tabular}{|c|c|c|c|c|c|c|c|c|}
\hline \multirow[b]{2}{*}{ Country and centre } & \multicolumn{4}{|c|}{ Men } & \multicolumn{4}{|c|}{ Women } \\
\hline & $n$ & $\%$ Mis-R & $\%$ Under-R & $\%$ Over-R & $n$ & $\%$ Mis-R & $\%$ Under-R & $\%$ Over-R \\
\hline Greece & 1312 & 21 & 20 & 1 & 1374 & 34 & 33 & 1 \\
\hline Spain & 1777 & 8 & 5 & 3 & 1443 & 15 & 14 & 1 \\
\hline Granada & 214 & 8 & 6 & 2 & 300 & 19 & 19 & 0 \\
\hline Murcia & 243 & 11 & 7 & 4 & 304 & 19 & 18 & 1 \\
\hline Navarra & 444 & 4 & 3 & 1 & 271 & 11 & 10 & 1 \\
\hline San Sebastian & 490 & 9 & 4 & 5 & 244 & 9 & 7 & 2 \\
\hline Asturias & 386 & 10 & 5 & 5 & 324 & 16 & 14 & 2 \\
\hline Italy & 1444 & 9 & 7 & 2 & 2512 & 17 & 16 & 1 \\
\hline Ragusa & 168 & 13 & 10 & 3 & 138 & 22 & 19 & 4 \\
\hline Naples & - & - & - & - & 403 & 20 & 19 & 1 \\
\hline Florence & 271 & 6 & 4 & 2 & 785 & 17 & 16 & 1 \\
\hline Turin & 677 & 9 & 8 & 2 & 392 & 19 & 18 & 1 \\
\hline Varese & 328 & 8 & 5 & 2 & 794 & 13 & 13 & 0 \\
\hline France & - & - & - & - & 4639 & 8 & 7 & 2 \\
\hline South coast & - & - & - & - & 612 & 7 & 6 & $\overline{1}$ \\
\hline South & - & - & - & - & 1396 & 10 & 8 & 2 \\
\hline North-west & - & - & - & - & 622 & 6 & 5 & 1 \\
\hline North-east & - & - & - & - & 2009 & 8 & 6 & 2 \\
\hline Germany & 2268 & 13 & 12 & 1 & 2150 & 16 & 15 & 1 \\
\hline Heidelberg & 1033 & 16 & 14 & 2 & 1087 & 16 & 15 & 1 \\
\hline Potsdam & 1235 & 11 & 10 & 1 & 1063 & 17 & 16 & 0 \\
\hline The Netherlands & 1024 & 12 & 9 & 3 & 2960 & 14 & 13 & 1 \\
\hline Bilthoven & 1024 & 12 & 9 & 3 & 1086 & 16 & 16 & 1 \\
\hline Utrecht & - & - & - & - & 1874 & 13 & 12 & 1 \\
\hline United Kingdom & 518 & 13 & 12 & 1 & 768 & 17 & 15 & 1 \\
\hline General population & 404 & 12 & 11 & 1 & 571 & 18 & 17 & 1 \\
\hline 'Health-conscious' & 114 & 17 & 15 & 2 & 197 & 12 & 10 & 2 \\
\hline Denmark & 1923 & 10 & 8 & 1 & 1995 & 15 & 13 & 2 \\
\hline Copenhagen & 1356 & 10 & 9 & 1 & 1485 & 16 & 14 & 1 \\
\hline Aarhus & 567 & 8 & 7 & 1 & 510 & 12 & 10 & 2 \\
\hline Sweden & 2765 & 13 & 11 & 1 & 3285 & 15 & 14 & 1 \\
\hline Malmö & 1421 & 15 & 14 & 1 & 1711 & 16 & 15 & 1 \\
\hline Umeå & 1344 & 10 & 8 & 2 & 1574 & 14 & 13 & 1 \\
\hline Norway & - & - & - & - & 1798 & 13 & 12 & 1 \\
\hline South \& East & - & - & - & - & 1136 & 13 & 12 & 1 \\
\hline North \& West & - & - & - & - & 662 & 13 & 11 & 2 \\
\hline
\end{tabular}


Physical activity in the EPIC calibration sample was available through two independent variables: physical activity at work, where the type of work of study participants was categorised into four levels (not employed, sedentary, standing and manual/heavy manual work $)^{17}$, and a score reflecting activities during leisure time.

Apart from the UK 'health-conscious' group, special diet reflected long-term health problems related to diet (e.g. hyperlipidaemia, hypertension, diabetes, stomach or intestinal problems), particularly in Umeå and, to a lesser extent, Greece.

To explain EI/BMR variability between EPIC centres and to speculate on potential causality of any of the mentioned factors, multivariate statistical models were used to determine the principal sources of EI/BMR variability. Mean and standard deviations of relevant variables were computed by sex-specific quartiles of BMI and, subsequently, EI/BMR.

In addition, multivariate unconditional logistic regression analyses were performed to investigate the role of variables associated with underreporting, by creating a dichotomous outcome $(1=$ extreme underreporters, with $\mathrm{EI} / \mathrm{BMR}<0.88 ; 0=$ participants with plausible values) used as the dependent variable in a regression model. Due to the marginal role of overreporting, the present analysis was restricted to underreporting. Age (five categories: <50, 50-55, 55$60,60-65$ and $\geq 65$ years), height (continuous), weight (sex-specific quartiles), physical activity (at work and, separately, during leisure time), smoking status (three categories: non-smokers, ex-smokers and smokers), special diet and day of the week (weekday vs. weekend day, Friday within the latter) were included in the statistical models. Categorical variables were fitted by means of dummy indicators. Since energy intake is strongly associated with EI/BMR (partial linear correlation higher than 0.90 ), it was not included in the various models considered. Educational level and season of recall were not included in the final model because they were not found to be statistically associated to the outcome, in contrast to previous observations ${ }^{19}$. Models with BMI instead of weight were also fitted.

Since underreporting and the distribution of its potential determinants differ between men and women, genderspecific analyses were performed. Throughout the work, significance level equal to $95 \%$ was used. All statistical analyses were performed with SAS, version $8.2^{20}$.

\section{Results}

The calibration sample has been described in detail

Table 2a Crude and adjusted ratio of energy intake to basal metabolic rate (EI/BMR) mean estimates for the total sample and after exclusion of misreporters (Mis-R): men

\begin{tabular}{|c|c|c|c|c|c|c|c|c|c|c|c|}
\hline \multirow[b]{3}{*}{ Country and centre } & \multirow[b]{3}{*}{$n$} & \multirow[b]{3}{*}{ Mis-R } & \multicolumn{4}{|c|}{ Total } & \multicolumn{4}{|c|}{ After exclusion } & \multirow[b]{3}{*}{ Low lim } \\
\hline & & & \multicolumn{2}{|c|}{ Crude } & \multicolumn{2}{|c|}{ Adjusted $^{*}$} & \multicolumn{2}{|c|}{ Crude } & \multicolumn{2}{|c|}{ Adjusted $^{\star}$} & \\
\hline & & & Mean & SD & Mean & $95 \% \mathrm{Cl}$ & Mean & SD & Mean & $95 \% \mathrm{Cl}$ & \\
\hline Greece & 1312 & 21 & 1.29 & 0.51 & 1.31 & $1.28-1.34$ & 1.41 & 0.39 & 1.42 & $1.40-1.45$ & 1.53 \\
\hline Spain & 1777 & 8 & 1.62 & 0.53 & 1.64 & $1.61-1.66$ & 1.61 & 0.42 & 1.63 & $1.61-1.65$ & 1.53 \\
\hline Granada & 214 & 8 & 1.55 & 0.50 & 1.60 & $1.54-1.67$ & 1.56 & 0.38 & 1.58 & $1.53-1.64$ & 1.49 \\
\hline Murcia & 243 & 11 & 1.57 & 0.57 & 1.58 & $1.51-1.64$ & 1.57 & 0.43 & 1.58 & $1.53-1.63$ & 1.49 \\
\hline Navarra & 444 & 4 & 1.57 & 0.44 & 1.57 & $1.53-1.62$ & 1.58 & 0.39 & 1.58 & $1.54-1.62$ & 1.51 \\
\hline San Sebastian & 490 & 9 & 1.72 & 0.54 & 1.73 & $1.69-1.78$ & 1.69 & 0.43 & 1.73 & $1.70-1.77$ & 1.51 \\
\hline Asturias & 386 & 10 & 1.63 & 0.58 & 1.64 & $1.60-1.69$ & 1.60 & 0.44 & 1.61 & $1.57-1.65$ & 1.51 \\
\hline Italy & 1444 & 9 & 1.51 & 0.50 & 1.48 & $1.46-1.51$ & 1.53 & 0.40 & 1.51 & $1.49-1.53$ & 1.53 \\
\hline Ragusa & 168 & 13 & 1.47 & 0.52 & 1.50 & $1.42-1.57$ & 1.51 & 0.41 & 1.53 & $1.47-1.59$ & 1.48 \\
\hline Florence & 271 & 6 & 1.51 & 0.47 & 1.49 & $1.43-1.55$ & 1.51 & 0.40 & 1.50 & $1.45-1.54$ & 1.50 \\
\hline Turin & 677 & 9 & 1.47 & 0.49 & 1.44 & $1.41-1.48$ & 1.51 & 0.40 & 1.49 & $1.46-1.52$ & 1.52 \\
\hline Varese & 328 & 8 & 1.59 & 0.51 & 1.55 & $1.50-1.60$ & 1.60 & 0.41 & 1.57 & $1.53-1.62$ & 1.50 \\
\hline Germany & 2268 & 13 & 1.39 & 0.48 & 1.44 & $1.42-1.46$ & 1.46 & 0.37 & 1.50 & $1.48-1.51$ & 1.53 \\
\hline Heidelberg & 1033 & 16 & 1.38 & 0.50 & 1.44 & $1.41-1.47$ & 1.45 & 0.37 & 1.50 & $1.47-1.52$ & 1.52 \\
\hline Potsdam & 1235 & 11 & 1.40 & 0.46 & 1.44 & $1.42-1.47$ & 1.47 & 0.37 & 1.50 & $1.48-1.52$ & 1.53 \\
\hline The Netherlands & 1024 & 12 & 1.47 & 0.53 & 1.49 & $1.46-1.53$ & 1.49 & 0.39 & 1.51 & $1.48-1.53$ & 1.52 \\
\hline Bilthoven & 1024 & 12 & 1.47 & 0.53 & 1.50 & $1.47-1.53$ & 1.49 & 0.39 & 1.51 & $1.48-1.53$ & 1.52 \\
\hline United Kingdom & 518 & 13 & 1.37 & 0.43 & 1.34 & $1.30-1.38$ & 1.44 & 0.34 & 1.41 & $1.37-1.45$ & 1.51 \\
\hline General population & 404 & 12 & 1.39 & 0.41 & 1.36 & $1.31-1.41$ & 1.45 & 0.33 & 1.43 & $1.39-1.47$ & 1.51 \\
\hline 'Health-conscious' & 114 & 17 & 1.33 & 0.47 & 1.28 & $1.19-1.37$ & 1.40 & 0.37 & 1.34 & $1.26-1.42$ & 1.47 \\
\hline Denmark & 1923 & 10 & 1.47 & 0.48 & 1.48 & $1.46-1.51$ & 1.51 & 0.40 & 1.52 & $1.50-1.54$ & 1.53 \\
\hline Copenhagen & 1356 & 10 & 1.45 & 0.48 & 1.47 & $1.44-1.50$ & 1.50 & 0.40 & 1.51 & $1.48-1.53$ & 1.53 \\
\hline Aarhus & 567 & 8 & 1.50 & 0.46 & 1.52 & $1.48-1.56$ & 1.54 & 0.40 & 1.55 & $1.52-1.59$ & 1.51 \\
\hline Sweden & 2765 & 13 & 1.42 & 0.49 & 1.38 & $1.37-1.40$ & 1.48 & 0.39 & 1.45 & $1.43-1.47$ & 1.53 \\
\hline Malmö & 1421 & 15 & 1.37 & 0.48 & 1.34 & $1.31-1.36$ & 1.45 & 0.38 & 1.42 & $1.40-1.45$ & 1.53 \\
\hline Umeá & 1344 & 10 & 1.47 & 0.50 & 1.43 & $1.41-1.46$ & 1.50 & 0.39 & 1.47 & $1.45-1.49$ & 1.53 \\
\hline
\end{tabular}

SD - standard deviation; $95 \% \mathrm{Cl}-95 \%$ confidence interval.

* Mean values were adjusted by body mass index, height, age at recall, day of recall (weekday vs. weekend day) and physical activity at work.

† Lower limit for evaluation of EI/BMR at the aggregate level, determined as a function of intra-individual variation and centre (country) sample size. 
elsewhere $^{13}$, and we list some important characteristics of the study participants in the Appendix. It can be seen that the frequency of special diets in the 24-HDR interviews was high, more so among women (ranging from $11 \%$ to $36 \%$ ) than men (from $7 \%$ to $27 \%$ ). In Table 1 we report the distribution of participants within the three categories of dietary reporting (extreme under-, normal and extreme overreporters) to characterise study subjects according to their reported energy intake.

Extreme underreporting at the individual level was higher in women than in men. The percentage of male participants below 0.88 was $10 \%$ overall, ranging from $3 \%$ in Navarra (Spain) to $20 \%$ in Greece. The percentage of overreporters ranged from 1\% (Navarra, general population in the UK, Greece, Potsdam in Germany, Malmö in Sweden, Aarhus and Copenhagen in Denmark) to 5\% (San Sebastian, Spain). The proportion of study participants identified as misreporters ranged from $4 \%$ (Navarra) to
21\% (Greece). Underreporting was heterogeneous across centres only in Italy, Germany and Sweden. A similar picture was observed for misreporting in general.

Among women, underreporting ranged from 5\% in North-west France to $33 \%$ in Greece, while most of the countries were between 13 and $16 \%$, with an overall percentage of $14 \%$. The percentage of overreporters in women ranged from $0.1 \%$ (Varese in Italy, Granada in Spain, Potsdam in Germany) to $4 \%$ (Ragusa in Italy) Country-specific analyses in women revealed that, across centres, the percentage of underreporters was statistically heterogeneous in all EPIC countries, except France, Germany and Norway. Overall, heterogeneous misreporting was also observed, except in Germany and Norway.

To evaluate underreporting at the population level, centre- and sex-specific EI/BMR means were calculated and are reported in Tables $2 \mathrm{a}$ and $2 \mathrm{~b}$. In men, EI/BMR means were above 1.55 only in Varese in Italy (1.59) and in

Table 2b Crude and adjusted ratio of energy intake to basal metabolic rate (El/BMR) mean estimates for the total sample and after exclusion of misreporters (Mis-R): women

\begin{tabular}{|c|c|c|c|c|c|c|c|c|c|c|c|}
\hline \multirow[b]{3}{*}{ Country and centre } & \multirow[b]{3}{*}{$n$} & \multirow[b]{3}{*}{ Mis-R } & \multicolumn{4}{|c|}{ Total } & \multicolumn{4}{|c|}{ After exclusion } & \multirow[b]{3}{*}{ Low limt } \\
\hline & & & \multicolumn{2}{|c|}{ Crude } & \multicolumn{2}{|c|}{ Adjusted $^{\star}$} & \multicolumn{2}{|c|}{ Crude } & \multicolumn{2}{|c|}{ Adjusted ${ }^{*}$} & \\
\hline & & & Mean & SD & Mean & $95 \% \mathrm{Cl}$ & Mean & SD & Mean & $95 \% \mathrm{Cl}$ & \\
\hline Greece & 1374 & 34 & 1.09 & 0.44 & 1.16 & $1.13-1.18$ & 1.29 & 0.34 & 1.34 & $1.31-1.36$ & 1.53 \\
\hline Spain & 1443 & 15 & 1.37 & 0.49 & 1.41 & $1.39-1.43$ & 1.45 & 0.40 & 1.49 & $1.46-1.51$ & 1.53 \\
\hline Granada & 300 & 19 & 1.24 & 0.42 & 1.31 & $1.26-1.36$ & 1.35 & 0.35 & 1.41 & $1.37-1.46$ & 1.50 \\
\hline Murcia & 304 & 19 & 1.36 & 0.52 & 1.41 & $1.35-1.46$ & 1.47 & 0.42 & 1.51 & $1.46-1.56$ & 1.50 \\
\hline Navarra & 271 & 11 & 1.38 & 0.44 & 1.40 & $1.35-1.46$ & 1.44 & 0.37 & 1.47 & $1.43-1.52$ & 1.50 \\
\hline San Sebastian & 244 & 9 & 1.51 & 0.50 & 1.51 & $1.46-1.57$ & 1.54 & 0.42 & 1.55 & $1.50-1.60$ & 1.50 \\
\hline Asturias & 324 & 16 & 1.38 & 0.52 & 1.42 & $1.37-1.47$ & 1.44 & 0.41 & 1.48 & $1.44-1.53$ & 1.50 \\
\hline Italy & 2512 & 17 & 1.33 & 0.47 & 1.34 & $1.32-1.36$ & 1.43 & 0.37 & 1.42 & $1.40-1.44$ & 1.53 \\
\hline Ragusa & 138 & 22 & 1.34 & 0.54 & 1.36 & $1.29-1.44$ & 1.41 & 0.37 & 1.42 & $1.35-1.50$ & 1.48 \\
\hline Naples & 403 & 20 & 1.30 & 0.48 & 1.38 & $1.34-1.43$ & 1.43 & 0.38 & 1.45 & $1.41-1.49$ & 1.51 \\
\hline Florence & 785 & 17 & 1.34 & 0.48 & 1.33 & $1.30-1.36$ & 1.43 & 0.36 & 1.42 & $1.40-1.45$ & 1.52 \\
\hline Turin & 392 & 19 & 1.31 & 0.47 & 1.33 & $1.28-1.37$ & 1.43 & 0.38 & 1.44 & $1.40-1.48$ & 1.51 \\
\hline Varese & 794 & 13 & 1.34 & 0.43 & 1.33 & $1.30-1.37$ & 1.42 & 0.37 & 1.40 & $1.37-1.43$ & 1.52 \\
\hline France & 4639 & 8 & 1.48 & 0.47 & 1.42 & $1.41-1.43$ & 1.50 & 0.38 & 1.47 & $1.46-1.48$ & 1.54 \\
\hline South coast & 612 & 7 & 1.44 & 0.47 & 1.36 & $1.32-1.39$ & 1.47 & 0.39 & 1.42 & $1.39-1.45$ & 1.52 \\
\hline South & 1396 & 10 & 1.48 & 0.49 & 1.43 & $1.40-1.45$ & 1.51 & 0.39 & 1.47 & $1.45-1.49$ & 1.53 \\
\hline North-west & 622 & 6 & 1.47 & 0.41 & 1.40 & $1.37-1.44$ & 1.49 & 0.37 & 1.46 & $1.43-1.49$ & 1.52 \\
\hline North-east & 2009 & 8 & 1.49 & 0.48 & 1.44 & $1.42-1.46$ & 1.51 & 0.38 & 1.48 & $1.47-1.50$ & 1.53 \\
\hline Germany & 2150 & 16 & 1.31 & 0.45 & 1.35 & $1.33-1.37$ & 1.41 & 0.36 & 1.44 & $1.42-1.46$ & 1.53 \\
\hline Heidelberg & 1087 & 16 & 1.34 & 0.47 & 1.36 & $1.33-1.38$ & 1.43 & 0.37 & 1.45 & $1.42-1.47$ & 1.52 \\
\hline Potsdam & 1063 & 17 & 1.28 & 0.44 & 1.35 & $1.32-1.38$ & 1.38 & 0.36 & 1.43 & $1.41-1.46$ & 1.52 \\
\hline The Netherlands & 2960 & 14 & 1.38 & 0.47 & 1.39 & $1.38-1.41$ & 1.46 & 0.37 & 1.48 & $1.46-1.49$ & 1.53 \\
\hline Bilthoven & 1086 & 16 & 1.37 & 0.49 & 1.37 & $1.35-1.40$ & 1.47 & 0.39 & 1.47 & $1.45-1.50$ & 1.52 \\
\hline Utrecht & 1874 & 13 & 1.38 & 0.45 & 1.41 & $1.38-1.43$ & 1.46 & 0.37 & 1.48 & $1.46-1.50$ & 1.53 \\
\hline United Kingdom & 768 & 17 & 1.29 & 0.45 & 1.28 & $1.25-1.31$ & 1.37 & 0.34 & 1.36 & $1.33-1.39$ & 1.52 \\
\hline General population & 571 & 18 & 1.26 & 0.42 & 1.27 & $1.23-1.30$ & 1.36 & 0.34 & 1.35 & $1.32-1.38$ & 1.51 \\
\hline 'Health-conscious' & 197 & 12 & 1.38 & 0.50 & 1.33 & $1.27-1.39$ & 1.40 & 0.35 & 1.39 & $1.33-1.44$ & 1.49 \\
\hline Denmark & 1995 & 15 & 1.38 & 0.50 & 1.39 & $1.37-1.41$ & 1.45 & 0.39 & 1.44 & $1.42-1.46$ & 1.53 \\
\hline Copenhagen & 1485 & 16 & 1.35 & 0.48 & 1.35 & $1.33-1.37$ & 1.43 & 0.38 & 1.42 & $1.40-1.44$ & 1.53 \\
\hline Aarhus & 510 & 12 & 1.49 & 0.54 & 1.51 & $1.47-1.55$ & 1.52 & 0.40 & 1.52 & $1.49-1.56$ & 1.51 \\
\hline Sweden & 3285 & 15 & 1.33 & 0.46 & 1.33 & $1.32-1.35$ & 1.42 & 0.37 & 1.42 & $1.40-1.43$ & 1.53 \\
\hline Malmö & 1711 & 16 & 1.30 & 0.45 & 1.31 & $1.29-1.34$ & 1.40 & 0.36 & 1.40 & $1.38-1.42$ & 1.53 \\
\hline Umeå & 1574 & 14 & 1.36 & 0.46 & 1.35 & $1.33-1.37$ & 1.44 & 0.37 & 1.44 & $1.42-1.45$ & 1.53 \\
\hline Norway & 1798 & 13 & 1.39 & 0.47 & 1.36 & $1.32-1.40$ & 1.46 & 0.38 & 1.44 & $1.42-1.47$ & 1.53 \\
\hline South \& East & 1136 & 13 & 1.39 & 0.47 & 1.35 & $1.31-1.39$ & 1.47 & 0.38 & 1.45 & $1.43-1.47$ & 1.52 \\
\hline North \& West & 662 & 13 & 1.40 & 0.47 & 1.37 & $1.33-1.41$ & 1.45 & 0.38 & 1.44 & $1.41-1.47$ & 1.52 \\
\hline
\end{tabular}

SD - standard deviation; $95 \% \mathrm{Cl}$ - 95\% confidence interval.

* Mean values were adjusted by body mass index, height, age at recall, day of recall (weekday vs. weekend day) and physical activity at work.

† Lower limit for evaluation of El/BMR at the aggregate level, determined as a function of intra-individual variation and centre (country) sample size. 
all Spanish centres. However, after exclusion of underand overreporters at the individual level and adjustment for BMI, height, age at recall, day of recall and physical activity at work, mean values were within acceptable limits also in the Italian centres of Florence (1.50) and Ragusa (1.53). The exclusion of extreme reporters was particularly effective. The crude mean and the mean computed after exclusion were appreciably different in Greece (1.29 vs. 1.41), the UK general population (1.39 vs. 1.45 ), the UK 'health-conscious' ( 1.33 vs. 1.40), Heidelberg in Germany (1.38 vs. 1.45$)$, Potsdam in Germany ( 1.40 vs. 1.47$)$ and Malmö in Sweden (1.37 vs. 1.45). In some centres the adjustment strengthened the tendency to increase mean values while in other situations the effect was the opposite. Overall, exclusion seemed to be more effective than adjustment.

Among women, crude EI/BMR means were always under the expected value of 1.55. By taking the lower limit computed at the population level, San Sebastian in Spain (1.51) was within the acceptable value. Exclusion of under- and overreporters and adjustment brought mean values within the centre-specific lower limits of the expected values of 1.55 only in Murcia in Spain (1.51) and Aarhus in Denmark (1.52). Similarly to men, exclusion had a stronger impact on mean values than adjustment, which is not surprising since the percentage of extreme reporters was higher among women than men. Crude means computed after exclusion of misreporters were higher than the means computed on all subjects. The difference was particularly evident in Turin in Italy (1.31 vs. 1.43), Naples in Italy (1.30 vs. 1.43), Granada in Spain (1.24 vs. 1.35), the UK general population (1.26 vs. 1.36 ), Greece (1.09 vs. 1.29), Heidelberg in Germany (1.34 vs. 1.43 ) and Potsdam in Germany (1.28 vs. 1.38).

Mean energy intake values are reported in Tables $3 \mathrm{a}$ and 3b. Among men, reported energy was relatively low in Greece (mean $2122 \mathrm{kcal} \mathrm{day}^{-1}$ ) and in the 'healthconscious' population in the UK $\left(2252 \mathrm{kcal} \mathrm{day}^{-1}\right)$. Substantially higher values were observed in Italy $\left(2614 \mathrm{kcalday}^{-1}\right)$, The Netherlands $\left(2726 \mathrm{kcalday}^{-1}\right)$, Denmark (2645 kcal day $\left.{ }^{-1}\right)$ and Spain $\left(2814 \mathrm{kcal} \mathrm{day}^{-1}\right)$. Among women, low values were observed in Greece $\left(1515 \mathrm{kcal} \mathrm{day}^{-1}\right)$, whereas in Denmark (1941 kcal day ${ }^{-1}$ ), The Netherlands (1944 kcalday $\left.{ }^{-1}\right)$, Norway $\left(1951 \mathrm{kcal} \mathrm{day}^{-1}\right)$ and France (1961 kcalday ${ }^{-1}$ ), mean values were higher.

Generally, energy intake values across centres were homogeneous within countries among men and women. Statistically significant differences between adjusted energy intake means, after exclusion, were observed among men within Spain - San Sebastian $\left(2990 \mathrm{kcal} \mathrm{day}^{-1}\right)$ vs. Granada $\left(2732 \mathrm{kcal} \mathrm{day}^{-1}\right)-$ and

Table 3a Crude and adjusted energy intake (kcal) mean estimates for the total sample and after exclusion of misreporters: men

\begin{tabular}{|c|c|c|c|c|c|c|c|c|c|}
\hline \multirow[b]{3}{*}{ Country and centre } & \multirow[b]{3}{*}{$n$} & \multicolumn{4}{|c|}{ Total } & \multicolumn{4}{|c|}{ After exclusion } \\
\hline & & \multicolumn{2}{|c|}{ Crude } & \multicolumn{2}{|c|}{ Adjusted* } & \multicolumn{2}{|c|}{ Crude } & \multicolumn{2}{|c|}{ Adjusted* } \\
\hline & & Mean & SD & Mean & SD & Mean & SD & Mean & SD \\
\hline Greece & 1312 & 2122 & 831 & 2280 & 871 & 2313 & 680 & 2471 & 697 \\
\hline Spain & 1777 & 2814 & 921 & 2846 & 879 & 2799 & 755 & 2834 & 703 \\
\hline Granada & 214 & 2638 & 817 & 2760 & 852 & 2663 & 631 & 2732 & 682 \\
\hline Murcia & 243 & 2677 & 978 & 2765 & 851 & 2675 & 744 & 2774 & 673 \\
\hline Navarra & 444 & 2706 & 796 & 2745 & 857 & 2719 & 714 & 2751 & 683 \\
\hline San Sebastian & 490 & 3077 & 961 & 2998 & 852 & 3032 & 778 & 2990 & 673 \\
\hline Asturias & 386 & 2788 & 953 & 2862 & 853 & 2752 & 784 & 2821 & 687 \\
\hline Italy & 1444 & 2614 & 847 & 2618 & 857 & 2652 & 703 & 2670 & 688 \\
\hline Ragusa & 168 & 2561 & 886 & 2628 & 846 & 2618 & 677 & 2677 & 675 \\
\hline Florence & 271 & 2660 & 846 & 2645 & 843 & 2657 & 752 & 2656 & 677 \\
\hline Turin & 677 & 2563 & 828 & 2553 & 848 & 2621 & 690 & 2629 & 681 \\
\hline Varese & 328 & 2705 & 861 & 2729 & 844 & 2726 & 698 & 2764 & 678 \\
\hline Germany & 2268 & 2485 & 834 & 2524 & 854 & 2600 & 665 & 2619 & 682 \\
\hline Heidelberg & 1033 & 2477 & 889 & 2511 & 852 & 2605 & 679 & 2606 & 681 \\
\hline Potsdam & 1235 & 2492 & 786 & 2537 & 844 & 2596 & 653 & 2630 & 674 \\
\hline The Netherlands & 1024 & 2726 & 966 & 2622 & 866 & 2771 & 731 & 2638 & 695 \\
\hline Bilthoven & 1024 & 2726 & 966 & 2626 & 864 & 2771 & 731 & 2640 & 694 \\
\hline United Kingdom & 518 & 2368 & 719 & 2331 & 845 & 2481 & 596 & 2456 & 682 \\
\hline General population & 404 & 2400 & 715 & 2379 & 841 & 2507 & 594 & 2502 & 678 \\
\hline 'Health-conscious' & 114 & 2252 & 725 & 2167 & 841 & 2382 & 595 & 2286 & 677 \\
\hline Denmark & 1923 & 2645 & 833 & 2631 & 860 & 2720 & 708 & 2693 & 690 \\
\hline Copenhagen & 1356 & 2609 & 833 & 2601 & 856 & 2690 & 707 & 2669 & 687 \\
\hline Aarhus & 567 & 2729 & 827 & 2703 & 849 & 2791 & 706 & 2752 & 681 \\
\hline Sweden & 2765 & 2412 & 812 & 2419 & 890 & 2508 & 658 & 2530 & 714 \\
\hline Malmö & 1421 & 2310 & 787 & 2359 & 878 & 2442 & 647 & 2511 & 705 \\
\hline Umeá & 1344 & 2520 & 824 & 2478 & 856 & 2573 & 662 & 2548 & 687 \\
\hline
\end{tabular}

SD - standard deviation.

- Mean values were adjusted by body mass index, height, age at recall, day of recall (weekday vs. weekend day) and physical activity at work. 
Table 3b Crude and adjusted energy intake (kcal) mean estimates for the total sample and after exclusion of misreporters: women

\begin{tabular}{|c|c|c|c|c|c|c|c|c|c|}
\hline \multirow[b]{3}{*}{ Country and centre } & \multirow[b]{3}{*}{$n$} & \multicolumn{4}{|c|}{ Total } & \multicolumn{4}{|c|}{ After exclusion } \\
\hline & & \multicolumn{2}{|c|}{ Crude } & \multicolumn{2}{|c|}{ Adjusted* } & \multicolumn{2}{|c|}{ Crude } & \multicolumn{2}{|c|}{ Adjusted* } \\
\hline & & Mean & SD & Mean & SD & Mean & SD & Mean & SD \\
\hline Greece & 1374 & 1515 & 598 & 1605 & 626 & 1774 & 474 & 1847 & 510 \\
\hline Spain & 1443 & 1899 & 663 & 1896 & 653 & 2003 & 552 & 1990 & 536 \\
\hline Granada & 300 & 1721 & 567 & 1749 & 622 & 1873 & 480 & 1875 & 508 \\
\hline Murcia & 304 & 1903 & 706 & 1886 & 623 & 2056 & 581 & 2019 & 508 \\
\hline Navarra & 271 & 1904 & 592 & 1893 & 619 & 1985 & 505 & 1973 & 507 \\
\hline San Sebastian & 244 & 2092 & 694 & 2052 & 620 & 2122 & 595 & 2097 & 507 \\
\hline Asturias & 324 & 1910 & 696 & 1915 & 620 & 1992 & 565 & 1987 & 507 \\
\hline Italy & 2512 & 1813 & 622 & 1864 & 628 & 1941 & 501 & 1967 & 505 \\
\hline Ragusa & 138 & 1838 & 736 & 1901 & 639 & 1928 & 537 & 1980 & 519 \\
\hline Naples & 403 & 1814 & 655 & 1930 & 633 & 1987 & 527 & 2026 & 505 \\
\hline Florence & 785 & 1829 & 632 & 1846 & 600 & 1947 & 484 & 1965 & 486 \\
\hline Turin & 392 & 1787 & 612 & 1839 & 630 & 1942 & 497 & 1982 & 506 \\
\hline Varese & 794 & 1806 & 578 & 1857 & 604 & 1915 & 500 & 1939 & 481 \\
\hline France & 4639 & 1961 & 620 & 1960 & 626 & 1994 & 508 & 2023 & 504 \\
\hline South coast & 612 & 1898 & 614 & 1873 & 611 & 1932 & 513 & 1953 & 492 \\
\hline South & 1396 & 1950 & 627 & 1966 & 607 & 1993 & 512 & 2029 & 489 \\
\hline North-west & 622 & 1936 & 538 & 1939 & 602 & 1968 & 479 & 2013 & 486 \\
\hline North-east & 2009 & 1997 & 638 & 1986 & 605 & 2023 & 510 & 2040 & 486 \\
\hline Germany & 2150 & 1834 & 619 & 1866 & 614 & 1964 & 504 & 1982 & 494 \\
\hline Heidelberg & 1087 & 1869 & 638 & 1873 & 613 & 1993 & 512 & 1994 & 491 \\
\hline Potsdam & 1063 & 1799 & 597 & 1859 & 609 & 1934 & 494 & 1970 & 488 \\
\hline The Netherlands & 2960 & 1944 & 637 & 1923 & 617 & 2059 & 515 & 2034 & 497 \\
\hline Bilthoven & 1086 & 1946 & 668 & 1894 & 610 & 2088 & 530 & 2026 & 491 \\
\hline Utrecht & 1874 & 1942 & 618 & 1940 & 622 & 2042 & 506 & 2039 & 499 \\
\hline United Kingdom & 768 & 1772 & 587 & 1770 & 603 & 1871 & 468 & 1878 & 485 \\
\hline General population & 571 & 1745 & 573 & 1750 & 598 & 1865 & 473 & 1867 & 479 \\
\hline 'Health-conscious' & 197 & 1851 & 621 & 1829 & 607 & 1885 & 457 & 1906 & 487 \\
\hline Denmark & 1995 & 1941 & 679 & 1929 & 624 & 2034 & 539 & 2003 & 500 \\
\hline Copenhagen & 1485 & 1895 & 654 & 1877 & 616 & 2000 & 529 & 1967 & 489 \\
\hline Aarhus & 510 & 2076 & 732 & 2090 & 629 & 2126 & 555 & 2110 & 508 \\
\hline Sweden & 3285 & 1847 & 614 & 1836 & 620 & 1962 & 501 & 1950 & 501 \\
\hline Malmö & 1711 & 1805 & 605 & 1817 & 621 & 1926 & 492 & 1930 & 498 \\
\hline Umeå & 1574 & 1892 & 621 & 1857 & 601 & 1999 & 509 & 1971 & 488 \\
\hline Norway & 1798 & 1951 & 636 & 1860 & 612 & 2043 & 520 & 1972 & 507 \\
\hline South \& East & 1136 & 1944 & 632 & 1850 & 623 & 2045 & 521 & 1980 & 516 \\
\hline North \& West & 662 & 1963 & 642 & 1874 & 608 & 2039 & 519 & 1966 & 507 \\
\hline
\end{tabular}

SD - standard deviation.

" Mean values were adjusted by body mass index, height, age at recall, day of recall (weekday vs. weekend day) and physical activity at work.

within Denmark - Aarhus ( $2752 \mathrm{kcal} \mathrm{day}^{-1}$ ) vs. Copenhagen $\left(2669 \mathrm{kcal} \mathrm{day}^{-1}\right)$. Similarly, among women, significant differences were observed within Spain - San Sebastian (2097 kcal day ${ }^{-1}$ ) vs. Granada ( $1875 \mathrm{kcal} \mathrm{day}^{-1}$ ) - and within Denmark - Aarhus (2110 kcal day ${ }^{-1}$ ) vs. Copenhagen $\left(1967 \mathrm{kcal} \mathrm{day}^{-1}\right)$. This corresponds to an absolute difference of $9 \%$ and $12 \%$ in Spain, and 3\% and $7 \%$ in Denmark, for men and women, respectively.

After exclusion of extreme reporters, energy intake means increased, as expected, in most of the centres. In Greece, due to the high percentage of participants identified as misreporters, estimates of reported energy intake increased from $2122 \mathrm{kcal} \mathrm{day}^{-1}$ (crude value) to $2471 \mathrm{kcalday}^{-1}$ (adjusted after exclusion) in men, and from $1515 \mathrm{kcalday}^{-1}$ (crude value) to $1847 \mathrm{kcalday}^{-1}$ (adjusted after exclusion) in women. Overall, after exclusion, the crude means were $3.3 \%$ and $5.8 \%$ higher in men and women, respectively. This is not surprising since the percentage of participants identified as underreporters according to Goldberg's cut-off was substantially higher than those identified as overreporters.

\section{Determinants of $\mathrm{EI} / \mathrm{BMR}$ variability}

In Tables $4 \mathrm{a}$ and $4 \mathrm{~b}$ we report means and distribution of some variables of interest for understanding EI/BMR variability by quartiles of sex-specific BMI. There is a strong inverse linear relationship between BMI and EI/BMR in both men and women. The difference in BMI means between the highest and the lowest EI/BMR quartiles is $16 \%$ for men and $13 \%$ for women. Reported energy intake tends to be underestimated among obese people (most likely at higher values), and overestimated among lean people (for lower values). Tables $5 \mathrm{a}$ and $5 \mathrm{~b}$ show sex-specific quartiles of EI/BMR. Energy intake explains the majority of its variability. It also seems that weight (and BMI) plays a role in explaining part of the 
Table 4a Mean and distribution of relevant variables by sexspecific quartiles of body mass index (BMI): men

\begin{tabular}{lcccc}
\hline & \multicolumn{4}{c}{ BMI quartile } \\
\cline { 2 - 5 } & 1 & 2 & 3 & 4 \\
\hline BMI (kg m & -2 & & \\
El/BMR & 22.9 & 25.6 & 27.6 & 31.6 \\
El (kcal) & 1.58 & 1.48 & 1.41 & 1.32 \\
BMR & 2607 & 2556 & 2504 & 2452 \\
Weight (kg) & 1656 & 1731 & 1783 & 1868 \\
Height (cm) & 71.1 & 78.2 & 83.9 & 93.8 \\
Age (years) & 175.4 & 174.3 & 173.7 & 172.4 \\
PA at work (\%) & 56.1 & 56.4 & 56.8 & 57.8 \\
$\quad$ Non-worker & 25.3 & 23.1 & 23.5 & 28.0 \\
Sedentary & 26.6 & 26.5 & 25.2 & 21.7 \\
Standing & 24.8 & 26.1 & 26.1 & 22.9 \\
$\quad$ (Heavy) Manual & 21.8 & 24.7 & 25.3 & 28.2 \\
PA at leisure (\%) & & & & \\
$\quad$ Low & 23.1 & 23.8 & 26.4 & 26.7 \\
$\quad$ Moderate & 26.0 & 25.8 & 24.1 & 24.1 \\
Intense & 25.6 & 25.6 & 24.4 & 24.3 \\
\hline
\end{tabular}

EI - energy intake; BMR - basal metabolic rate; PA - physical activity.

EI/BMR heterogeneity. Physical activity should also be taken into account since it is one of the components that determine individual energy intake. PA at work is significantly related to EI/BMR, the higher the latter the more active the type of work, and this association is stronger in men than in women. As for PA at leisure time, once again higher EI/BMR ratios are associated with higher activity, and the evidence is stronger for men than for women.

After adjustment for age, height, special diet, smoking status and physical activity at work, unconditional logistic regression showed a strong positive association between weight (and BMI) and underreporting (Table 6). The odds ratio (OR) of being an underreporter for the highest vs. the lowest quartile of weight was 3.79 (95\% CI 3.10-4.62) in

Table 4b Mean and distribution of relevant variables by sexspecific quartiles of body mass index (BMI): women

\begin{tabular}{lcccc} 
& \multicolumn{4}{c}{ BMI quartile } \\
\cline { 2 - 5 } & 1 & 2 & 3 & 4 \\
\hline BMI (kg m ${ }^{-2}$ ) & 20.7 & 23.5 & 26.1 & 31.5 \\
El/BMR & 1.55 & 1.41 & 1.32 & 1.17 \\
El (kcal) & 2003 & 1901 & 1849 & 1744 \\
BMR & 1293 & 1350 & 1401 & 1501 \\
Weight (kg) & 56.1 & 62.6 & 68.6 & 80.5 \\
Height (cm) & 163.22 & 162.3 & 161.6 & 159.7 \\
Age (years) & 53.4 & 54.8 & 55.9 & 57.1 \\
PA at work (\%) & & & & \\
$\quad$ Non-worker & 20.0 & 22.3 & 26.0 & 31.6 \\
Sedentany & 28.3 & 27.0 & 24.1 & 20.6 \\
Standing & 27.3 & 26.0 & 24.5 & 22.2 \\
$\quad$ (Heavy) Manual & 19.8 & 24.2 & 27.8 & 28.2 \\
PA at leisure (\%) & & & & \\
$\quad$ Low & 24.8 & 24.2 & 24.9 & 26.1 \\
$\quad$ Moderate & 24.8 & 24.6 & 24.6 & 26.0 \\
$\quad$ Intense & 23.0 & 25.0 & 26.0 & 26.0 \\
\hline
\end{tabular}

EJ - energy intake; BMR - basal melabolic rate; PA - physical activity:
Table 5a Mean and distribution of relevant variables by sexspecific quartiles of ratio of energy intake to basal metabolic rate (El/BMR): men

\begin{tabular}{lcccc}
\hline & \multicolumn{5}{c}{ El/BMR quartile } \\
\cline { 2 - 5 } & 1 & 2 & 3 & 4 \\
\hline BMI (kg m ${ }^{-2}$ ) & 28.0 & 27.1 & 26.6 & 26.0 \\
El/BMR & 0.88 & 1.25 & 1.54 & 2.11 \\
El (kcal) & 1590 & 2221 & 2697 & 3610 \\
BMR & 1884 & 1779 & 1746 & 1710 \\
Weight (kg) & 85.4 & 82.6 & 80.7 & 78.6 \\
Height (cm) & 174.1 & 174.5 & 174.0 & 173.3 \\
Age (years) & 57.0 & 56.5 & 56.7 & 56.7 \\
PA at work (\%) & & & & \\
$\quad$ Non-worker & 27.4 & 23.6 & 25.0 & 24.0 \\
Sedentary & 25.8 & 27.2 & 24.8 & 22.3 \\
Standing & 24.7 & 25.5 & 25.0 & 24.8 \\
$\quad$ (Heavy) Manual & 19.3 & 22.5 & 25.6 & 32.6 \\
PA at leisure (\%) & & & & \\
$\quad$ Low & 26.4 & 26.1 & 24.8 & 22.6 \\
$\quad$ Moderate & 25.3 & 25.0 & 24.8 & 24.9 \\
Intense & 23.4 & 24.1 & 25.4 & 27.3 \\
\hline
\end{tabular}

BMI - body mass index; PA - physical activity.

men and 4.75 (95\% CI 4.12-5.42) in women, indicating that overweight subjects are significantly more likely to underestimate energy intake than slim subjects. ORs for BMI were surprisingly similar to the estimates observed for weight in both men and women. The effect of age was slightly higher in men $(0.58,95 \% \mathrm{CI} 0.45-0.77)$ than in women $(0.74,95 \% \mathrm{CI} 0.63-0.88)$ for the highest age category. Physical activity at work was, as expected, inversely associated with underreporting, with similar effects in the two genders, while no effect was observed for leisure physical activity. Recalling the weekend diet lowered the risk of reporting implausible energy values. Current smokers (vs. non-smokers) showed a significant OR only in women $(1.37,95 \%$ CI 1.22-1.54). Relatively

Table 5b Mean and distribution of relevant variables by sexspecific quartiles of ratio of energy intake to basal metabolic rate (EI/BMR): women

\begin{tabular}{lcccc}
\hline & \multicolumn{5}{c}{ El/BMR quartile } \\
\cline { 2 - 5 } & 1 & 2 & 3 & 4 \\
\hline BMI (kg m ${ }^{-2}$ ) & 27.5 & 25.7 & 24.8 & 23.8 \\
El/BMR & 0.82 & 1.17 & 1.46 & 1.99 \\
El (kcal) & 1171 & 1632 & 2005 & 2689 \\
BMR & 1426 & 1390 & 1376 & 1352 \\
Weight (kg) & 72.1 & 68.0 & 66.4 & 63.8 \\
Height (cm) & 160.7 & 161.6 & 162.0 & 162.3 \\
Age (years) & 55.8 & 55.6 & 55.1 & 54.8 \\
PA at work (\%) & & & & \\
Non-worker & 28.5 & 25.4 & 23.4 & 22.8 \\
Sedentary & 24.0 & 24.4 & 27.1 & 24.4 \\
Standing & 22.3 & 24.8 & 26.0 & 26.9 \\
$\quad$ (Heavy) Manual & 23.9 & 24.7 & 24.4 & 26.9 \\
PA at leisure (\%) & & & & \\
$\quad$ Low & 25.8 & 25.2 & 25.5 & 23.4 \\
$\quad$ Moderate & 24.4 & 25.2 & 25.0 & 25.5 \\
Intense & 25.7 & 24.3 & 24.7 & 25.3 \\
\hline
\end{tabular}

BMI - body mass index; PA - physical activity. 


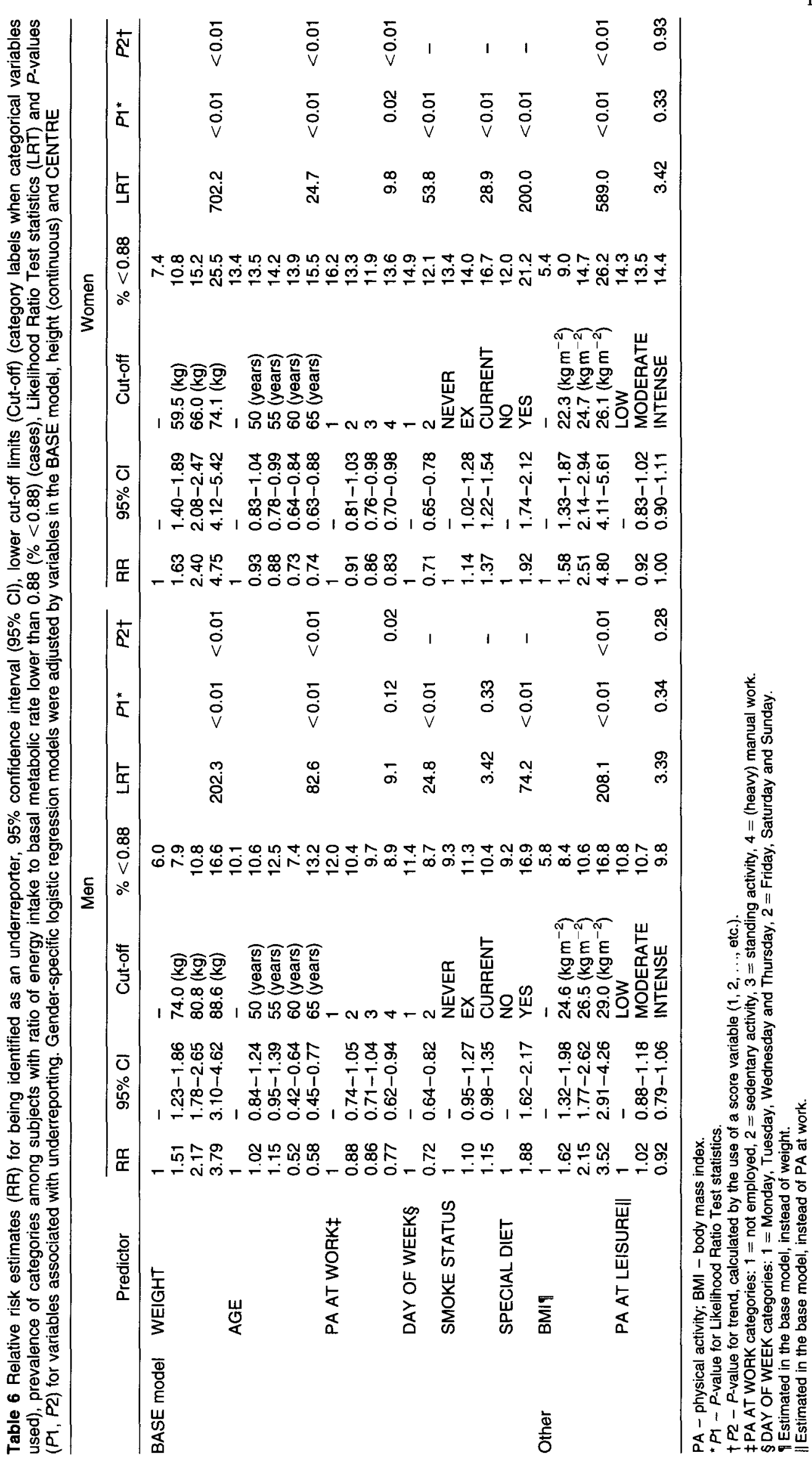


high odds ratios were observed for participants who reported following a special diet on the recalled day.

When centre- and sex-specific quartiles were used, results were similar (data not shown). Fitting models with different predictors, we also checked that the regression parameters for the variables that were consistently included (physical activity, special diet, day of the week and smoking status) did not vary substantially.

\section{Discussion}

In the present work we evaluated misreporting in the EPIC 24-HDR data. In the EPIC calibration sample there is evidence of underreporting, while overreporting has only a minor impact. Using Goldberg's cut-off points it was possible to identify centres at the aggregate level and study participants at the individual level as extreme underreporters, after considering between- and within-subject variability of EI/BMR components. At the aggregate level we observed EI/BMR means under the expected value of 1.55 in the vast majority of the EPIC centres. This cut-off level was chosen as the reference value given the calibration study population's age and physical activity. Adjusting for possible confounding changed the magnitude of estimates but did not substantially alter the ranking of centres. Notably, in Bilthoven (The Netherlands), where the study participants are younger than in the rest of the study, adjustment lowered mean energy estimates due to the observed negative correlation between age and reported energy intake. Adjusted means for energy were $7.5 \%$ and $5.9 \%$ lower than crude estimates in men and women, respectively.

Values of EI/BMR below 0.88 at the individual level are very likely to be the result of variations in reported energy intake beyond day-to-day variability. Analyses conducted at the individual level revealed that the percentage of people identified as extreme underreporters was always under 13\% in men (except Greece, 20\%) and under 17\% in women (except Greece, 33\%). Study participants in Greece have among the lowest values for physical activity, which might partially explain the extremely low values for self-reported energy intake. However, a recent study to validate protein intake through urinary nitrogen measurements in the EPIC 24-HDR ${ }^{21}$ showed evidence of underestimation of protein intake in Greece, supporting the interpretation that the underreporting of EI observed in the present study is real and not due to lower than expected physical activity.

Underreporting was generally heterogeneously distributed among countries, but homogeneously among centres within the different countries, in both male and female study populations.

In the EPIC 24-HDR data we observed an inverse linear relationship between BMI (or weight) and EI/BMR, thus suggesting that obese (or overweight) people tend to underreport energy intake. This association seems to be equally present in men and women, but is slightly stronger among the latter, a phenomenon previously reported in the literature ${ }^{5,22-28}$. Moreover, logistic regression analyses suggested that participants in the top BMI quartile have a considerably higher probability of being identified as an extreme underreporter than do participants with plausible values.

However, there are limitations to this interpretation when inferring a possible relationship between BMI and underreporting. First of all, this conclusion is based on the assumption that physical activity is constant in the population. Obese people may, however, be physically less active than non-obese, and actually have lower energy intakes, so the uniformly accepted PAL value of 1.55 for the general population may not apply equally to these subjects. Secondly, although the use of Goldberg's limits to identify under- and overreporters is very useful, a PAL of 1.55 assumes a sedentary lifestyle. This figure was chosen by the authors in order to avoid overestimation of underreporting. However, physical activity is very heterogeneous within any given population, and may be associated with a particular group of people. In the present work it has been assumed that 1.55 was a reasonable choice owing to the age span and other characteristics of the EPIC calibration sample.

Two indicators for physical activity were considered throughout the analyses. These variables do not provide individual quantitative estimates, but allow study participants to be ranked according to type of physical activity at work or during leisure. Their use made it possible to take into account the differences in participants' physical activity and to correct for possible confounding effects when calculating adjusted means or risk ratio estimates.

Furthermore, it is assumed that the equation proposed by Schofield et al. ${ }^{16}$ for BMR works equally well for all subjects in a given population. The linear relationships of height and weight, stratified by age group and gender, to estimate the basal metabolic rate may work less accurately for overweight people. These equations may lack precision because they are supposed to work well on average, statistically speaking, but not necessarily at the individual level. Moreover, a non-linear relationship may exist between BMR and weight, specifically for high values of weight. This would lead to imprecise estimates of BMR for a particular category of subjects (for example obese people), thus weakening the validity of estimated BMR. In a recent work, Black ${ }^{11}$ observed a non-linear relationship between estimated and measured BMR in women, suggesting that BMR of obese subjects may be overestimated, thus accentuating the extent of underreporting evaluated with EI/BMR. However, an appreciable effect seems to be present only for women with $\mathrm{BMI}>35 \mathrm{~kg} \mathrm{~m}^{-2}$, which represents only $3.6 \%$ of women in the EPIC 24-HDRs.

The evaluation of the relationship between EI/BMR and BMI (or weight) is problematic since both terms are a 
function of height and weight, and therefore share a common source of variation. Part of the statistical association observed may simply be due to the common source of variability between EI/BMR and its components and not to a true causal relationship between weight (or BMI) and age and underreporting.

In this study, the hypothesis that some factors, specifically BMI (and weight), are significant determinants of underreporting is based on a considerable list of assumptions. The authors are aware of the limitations of this speculation, but intend to provide insights into questions that will very likely be one of the most challenging fields of research in nutritional epidemiology. We therefore strongly believe that there is room for an ad boc study designed to further evaluate and test our conjectures.

In a multi-centre study, the aim of calibration is to express dietary measurements on a common scale and to correct for bias due to measurement errors in the DQ measurements. Measurement error attenuates the relationship between exposure and disease towards the null hypothesis of no association. The objective of calibration is therefore to estimate the attenuation parameter $\lambda$ to adjust dietary exposure assessments so that relative risk estimates calculated for a quantitative per unit difference in exposure level are no longer biased by errors in DQ measurements ${ }^{4,29,30}$. In the EPIC calibration setting, attenuation coefficients are estimated by regressing the 24-HDR reference measurements $(R)$ on DQ measurements under the assumption, among others, that $R$ is linearly related to true habitual intake $(T)$ as $R=$ $\alpha_{R}+\beta_{R} T+\varepsilon_{R}, \quad$ where $\quad \beta_{R}=1, \quad E\left[e_{R} \mid T\right]=0 \quad$ and $\operatorname{Var}\left(e_{R}\right)=\sigma_{e R}^{2}$. It is therefore assumed that the reference measurements are unbiased, or - equivalently - that error is strictly random, after the $\alpha_{R}$ term captures the systematic component.

In a multi-centre setting, calibration and data analysis have a within-group (countries or centres) component and a between-group (ecological) component. Underreporting in the 24-HDR indicates that the EPIC reference measurements are not unbiased at the group level. However, if underreporting is distributed randomly between subjects within groups, 24-HDR can still be used to calibrate DQ measurements onto a reference scale without absolute validity, but which is common across subjects. Moreover, if the degree of underreporting is approximately constant across study population groups, the questionnaire measurements can still be calibrated for between-group calibration ${ }^{7}$. After exclusion of misreporters, adjusted EI/BMR means were consistently less than $10 \%$ different from the expected value of 1.55 for PAL (except for women in Greece and in the UK), with overall differences equal to $4.0 \%$ and $7.4 \%$ for men and women, respectively. These results seem to be confirmed by the validation study on protein intake in the EPIC 24-HDR previously mentioned ${ }^{21}$, where very similar results on underestimation of protein intakes were observed. Moreover, a similar picture was observed after considering PAL values equal to 1.65 , thus assuming higher PAL for the EPIC calibration sub-sample.

However, the fact that some factors may have a causal effect on underreporting implies that measurement error in the 24-HDR estimates for energy intake also contains a systematic component. It reflects the tendency of study participants with specific characteristics (e.g. BMI, age, etc.) to under- or overreport dietary intake systematically and may be the result of within-person systematic error not randomly distributed between subjects. Kipnis et al. ${ }^{31}$ refer to it as person- and group-specific bias in reporting dietary intakes. Several strategies are advisable; for example, the use of BMI-specific attenuation factors. On the basis of several studies that reported serious underreporting in groups of people with high $\mathrm{BMI}^{26-28}$, Prentice $^{32}$ proposed a model in which the degree of attenuation depends on the individual. This model suggests that the overall level of attenuation may be far greater than previously thought. Although the effect of BMI on underreporting has been suggested repeatedly and different calibration approaches discussed, no uniformly accepted evidence about the effect of BMI on attenuation has been reached ${ }^{33}$

The prevalence of a special diet at recall is high (16.3\% and $20.6 \%$ in men and women, respectively), and $26.3 \%$ and $31.3 \%$ of extreme male and female underreporters had a special diet during the recall. These values undoubtedly require further evaluation.

In a recent paper Black ${ }^{18}$ discusses the sensitivity and specificity of the Goldberg cut-off for EI/BMR to identify extreme underreporters. The use of 1.55 for PAL to determine the individual cut-off point to identify underreporters has moderately low sensitivity but extremely high specificity, meaning that all of the participants identified as high underreporters are very likely to have truly underestimated energy intake, while some of the energy measurements considered to be plausible were effectively underestimated. This seems to strengthen the validity of our findings, since potential misclassification of study participants according to underreporting status, which is likely to be the case here, would lead to weaker effects.

\section{Acknowledgements}

The work described in this paper was carried out with financial support of the 'Europe Against Cancer' Programme of the European Commision (SANCO); Ligue contre le Cancer (France); Société 3M (France); Mutuelle Générale de l'Education Nationale; Institut National de la Santé et de la Recherche Médicale (INSERM); Institute Gustave Roussy; German Cancer Aid; German Cancer Research Centre; German Federal Ministry of Education and Research; Danish Cancer Society; Health Research 
Fund (FIS) of the Spanish Ministry of Health; the Spanish Regional Governments of Andalucia, Asturias, Basque Country, Murcia and Navarra; Cancer Research UK; Medical Research Council, UK; Stroke Association, UK; British Heart Foundation; Department of Health, UK; Food Standards Agency, UK; Wellcome Trust, UK; Greek Ministry of Health; Greek Ministry of Education; Italian Association for Research on Cancer; Italian National Research Council; Dutch Ministry of Public Health, Welfare and Sports; Dutch Prevention Funds; LK Research Funds; Dutch ZON (Zorg Onderzoek Nederland); World Cancer Research Fund; Swedish Cancer Society; Swedish Scientific Council; Regional Government of Skane, Sweden; Norwegian Cancer Society; Norwegian Research Council. Partial support for the publication of this supplement was provided by the Centre de Recherche et d'Information Nutritionnelles (CERIN).

In addition, we wish to thank all study participants for their co-operation and all interviewers who participated in the fieldwork studies in each EPIC centre

\section{References}

1 Riboli E, Kaaks R. The EPIC Project: rationale and study design. European Prospective Investigation into Cancer and Nutrition. Int. J. Epidemiol. 1997; 26(Suppl. 1): S6-14.

2 Riboli E, Hunt KJ, Slimani N, Ferrari P, Norat T, Fahey M, et al. European Prospective Investigation into Cancer and Nutrition (EPIC): study populations and data collection. Public Health Nutr. 2002; 5(6B): 1113-24.

3 Willett $W$. An overview of issues related to the correction of non-differential exposure measurement error in epidemiologic studies. Stat. Med. 1989; 8: 1031-40, discussion 1071-3.

4 Rosner B, Willett WC, Spiegelman D. Correction of logistic regression relative risk estimates and confidence intervals for systematic within-person measurement error. Stat. Med. 1989; 8: $1051-69$.

5 Bingham SA, Cassidy A, Cole TJ, Welch A, Runswick SA, Black $\mathrm{AE}$, et al. Validation of weighed records and other methods of dietary assessment using the $24 \mathrm{~h}$ urine nitrogen technique and other biological markers. Br.J. Nutr. 1995; 73: 531-50.

6 Black AE, Bingham SA, Johansson G, Coward WA. Validation of dietary intakes of protein and energy against 24 hour urinary $N$ and DLW energy expenditure in middle-aged women, retired men and post-obese subjects: comparisons with validation against presumed energy requirements. Eur. J. Clin. Nutr. 1997; 51: 405-13.

7 Riboli E, Kaaks R. The challenge of multi-center cohort studies in the search for diet and cancer links linvited commentary]. Am. J. Epidemiol. 2000; 151: 371-4.

8 Slimani N, Deharveng G, Charrondière RU, van Kappel AL, Ocké MC, Welch A, et al. Structure of the standardized computerized 24-h diet recall interview used as reference method in the 22 centers participating in the EPIC project. European Prospective Investigation into Cancer and Nutrition. Comput. Meth. Programs Biomed. 1999; 58: 251-66.

9 Black AE, Welch AA, Bingham SA. Validation of dietary intakes measured by diet history against $24 \mathrm{~h}$ urinary nitrogen excretion and energy expenditure measured by the doubly-labelled water method in middle-aged women. Br. J. Nutr. 2000; 83: 341-54.

10 Goldberg GR, Black AE, Jebb SA, Cole TJ, Murgatroyd PR, Coward WA, Prentice AM. Critical evaluation of energy intake data using fundamental principles of energy physiology: 1 . Derivation of cut-off limits to identify underrecording. Eur. J. Clin. Nutr. 1991; 45: 569-81.

11 Black AE. Critical evaluation of energy intake using the Goldberg cut-off for energy intake: basal metabolic rate. A practical guide to its calculation, use and limitations. Int. J. Obes. Relat. Metab. Disord. 2000; 24: 1119-30.

12 Kaaks R, Riboli E, van Staveren W. Sample size requirements for calibration studies of dietary intake measurements in prospective cohort investigations. Am. J. Epidemiol. 1995; 142: $557-65$.

13 Slimani N, Kaaks R, Ferrari P, Casagrande C, Clavel-Chapelon $\mathrm{F}$, Lotze $\mathrm{G}$, et al. European Prospective Investigation into Cancer and Nutrition (EPIC) calibration study: rationale, design and population characteristics. Public Healtb Nutr. 2002; 5(6B): 1125-45.

14 Charrondière UR, Vignat J, Møller A, Ireland J, Becker W, Church S, et al. The European Nutrient Database (ENDB) for nutritional epidemiology. J. Food Comp. Anal. 2002; 15(4): 435-51.

15 Deharveng G, Charrondière UR, Slimani N, Southgate DA, Riboli E. Comparison of nutrients in the food composition tables available in the nine European countries participating in EPIC. European Prospective Investigation into Cancer and Nutrition. Eur. J. Clin. Nutr. 1999; 53: 60-79.

16 Schofield WN, Scofield C, James WPT. Basal metabolic rate. Hum. Nutr. Clin. Nutr. 1985; 39C(Suppl. 1): 1-96.

17 Haftenberger M, Schuit AJ, Tormo MJ, Boeing $H$, Wareham $\mathrm{N}$, Bueno-de-Mesquita $\mathrm{HB}$, ef al. Physical activity of subjects aged 50-64 years involved in the European Prospective Investigation into Cancer and Nutrition (EPIC). Public Health Nutr. 2002; 5(6B): 1163-77.

18 Black AE. The sensitivity and the specificity of the Goldberg cut-off for EI:BMR for identifying diet reports of poor validity. Eur. J. Clin. Nutr. 2000; 51: 405-13.

19 Gnardellis C, Boulou C, Trichopoulou A. Magnitude, determinants and impact of under-reporting of energy intake in a cohort study in Greece. Public Healtb Nutr. 1998; 1: $131-7$.

20 SAS Institute, Inc. SAS/STAT User's Guide: Version 8.2. Cary, NC: SAS Institute Inc., 2001.

21 Slimani N, Bingham S, Runswick S, Ferrari P, Day N, Welch A, et al. Group level validation of protein intakes estimated by 24-hour diet recall and dietary questionnaires against 24 hour urinary nitrogen in the EPIC calibration study Submitted for publication.

22 Zhang J, Temme EH, Kesteloot H. Sex ratio of total energy intake in adults: an analysis of dietary surveys. Eur. J. Clin. Nutr. 1999; 53: 542-51.

23 Hebert JR, Ma Y, Clemow L, Ockene IS, Sapetia G, Stane EJ 3rd, et al. Gender differences in social desirability and social approval bias in dietary self-report. Am. J. Epidemiol. 1997; 146: $1046-55$

24 Black AE, Prentice AM, Goldberg GR, Jebb SA, Bingham SA, Livingstone $\mathrm{MB}$, et al. Measurements of total energy expenditure provide insights into the validity of dietary measurements of energy intake. J. Am. Diet. Assoc. 1993; 93: 572-9

25 Voss S, Kroke A, Klipstein-Grobusch K, Boeing H. Is macronutrient composition of dietary intake data affected by underreporting? Results from the EPIC-Potsdam Study. European Prospective Investigation into Cancer and Nutrition. Eur. J. Clin. Nutr. 1998; 52: 119-26.

26 Bandini LG, Schoeller DA, Cyr HN, Dietz WH. Validity of reported energy intake in obese and nonobese adolescents. Am.J. Clin. Nutr. 1990; 52: 421-5.

27 Heitmann BL. The influence of fatness, weight change, slimming history and other lifestyle variables on diet reporting in Danish men and women aged 35-65 years. Int.J. Obes, 1993; 17: 329-36. 
28 Heitmann BL, Lissner L. Dietary underreporting by obese individuals - is it specific or non- specific? Br. Med.J. 1995 311: 986-9.

29 Kaaks R, Riboli E, van Staveren W. Calibration of dietary intake measurements in prospective cohort studies. $\mathrm{Am}$. J. Epidemiol. 1995; 142: 548-56.

30 Kaaks R, Riboli E. Validation and calibration of dietary intake measurements in the EPIC project: methodological considerations. European Prospective Investigation into Cancer and Nutrition. Int. J. Epidemiol. 1997; 26(Suppl. 1): S15-25.

31 Kipnis V, Carroll RJ, Freedman LS, Li L. A new dietary measurement error model and its implications for the estimation of relative risk: application to four calibration studies. Am. J. Epidemiol. 1999; 150: 642-51.

32 Prentice R. Measurement error and results from analytic epidemiology: dietary fat and breast cancer. J. Natl. Cancer Inst. 1996; 88: 1738-47.

33 Kipnis V, Ferrari P, Riboli E, Slimani N, Midthune D, Carroll $\mathrm{RJ}$, et al. Attenuation (bias towards the null) in risk and its dependence on body mass index: results from calibration studies using the urinary nitrogen excretion biomarker. Manuscript in preparation.

\section{Appendix}

Table A1 Age, anthropometry and frequency of special diet at recall in the European Prospective Investigation into Cancer and Nutrition (EPIC) calibration sub-populations: men

\begin{tabular}{|c|c|c|c|c|c|c|c|c|c|c|}
\hline \multirow[b]{2}{*}{ Country and centre } & \multirow[b]{2}{*}{$n$} & \multicolumn{2}{|c|}{ Age (years)* } & \multicolumn{2}{|c|}{ Height $(\mathrm{cm})$} & \multicolumn{2}{|c|}{ Weight (kg) } & \multicolumn{2}{|c|}{$\mathrm{BMI}\left(\mathrm{kgm}^{-2}\right)$} & \multirow[b]{2}{*}{$\%$ Special diet } \\
\hline & & Mean & SD & Mean & SD & Mean & SD & Mean & SD & \\
\hline Greece & 1312 & 60.5 & 9.8 & 168.5 & 6.7 & 80.8 & 11.8 & 28.4 & 3.7 & 25 \\
\hline Spain & 1777 & 55.1 & 7.4 & 169.9 & 6.3 & 80.2 & 10.6 & 27.8 & 3.3 & 14 \\
\hline Granada & 214 & 58.1 & 6.7 & 169.2 & 6.4 & 82.2 & 10.6 & 28.7 & 3.3 & 22 \\
\hline Murcia & 243 & 55.6 & 7.4 & 168.4 & 6.0 & 78.1 & 10.0 & 27.6 & 3.3 & 9 \\
\hline Navarra & 444 & 56.3 & 6.8 & 169.1 & 6.0 & 80.1 & 9.9 & 28.0 & 3.2 & 20 \\
\hline San Sebastian & 490 & 51.5 & 6.8 & 171.7 & 6.3 & 80.3 & 10.9 & 27.2 & 3.2 & 6 \\
\hline Asturias & 386 & 56.2 & 7.5 & 169.9 & 6.4 & 80.5 & 11.0 & 27.9 & 3.2 & 18 \\
\hline Italy & 1444 & 55.2 & 7.0 & 171.7 & 6.8 & 78.3 & 10.8 & 26.5 & 3.2 & 8 \\
\hline Ragusa & 168 & 53.5 & 6.8 & 168.9 & 6.1 & 78.2 & 11.7 & 27.4 & 3.7 & 3 \\
\hline Florence & 271 & 54.4 & 7.3 & 173.0 & 6.7 & 79.1 & 11.2 & 26.4 & 3.3 & 10 \\
\hline Turin & 677 & 55.0 & 7.0 & 171.7 & 6.9 & 78.2 & 10.5 & 26.5 & 3.0 & 7 \\
\hline Varese & 328 & 57.1 & 6.2 & 171.8 & 6.7 & 77.6 & 10.6 & 26.3 & 3.2 & 12 \\
\hline Germany & 2268 & 54.6 & 7.3 & 175.3 & 6.6 & 83.2 & 12.1 & 27.1 & 3.6 & 19 \\
\hline Heidelberg & 1033 & 53.7 & 7.0 & 175.9 & 6.6 & 83.3 & 12.4 & 26.9 & 3.7 & 20 \\
\hline Potsdam & 1235 & 55.4 & 7.4 & 174.8 & 6.6 & 83.1 & 11.8 & 27.2 & 3.6 & 18 \\
\hline The Netherlands & 1024 & 50.0 & 7.4 & 177.7 & 7.1 & 83.8 & 12.5 & 26.5 & 3.6 & 6 \\
\hline Bilthoven & 1024 & 50.0 & 7.4 & 177.7 & 7.1 & 83.8 & 12.5 & 26.5 & 3.6 & 6 \\
\hline United Kingdom & 518 & 57.5 & 8.9 & 175.9 & 7.1 & 79.5 & 11.2 & 25.7 & 3.5 & 27 \\
\hline General population & 404 & 58.1 & 9.1 & 175.4 & 7.1 & 81.1 & 11.1 & 26.4 & 3.3 & 12 \\
\hline 'Health-conscious' & 114 & 55.4 & 7.7 & 177.6 & 7.0 & 73.7 & 9.3 & 23.4 & 2.8 & 81 \\
\hline Denmark & 1923 & 56.7 & 4.3 & 177.1 & 6.5 & 83.4 & 12.2 & 26.6 & 3.6 & 7 \\
\hline Copenhagen & 1356 & 57.0 & 4.4 & 177.2 & 6.7 & 83.5 & 12.5 & 26.6 & 3.6 & 8 \\
\hline Aarhus & 567 & 56.0 & 4.2 & 176.9 & 6.2 & 83.0 & 11.6 & 26.5 & 3.4 & 4 \\
\hline Sweden & 2765 & 61.1 & 7.3 & 176.7 & 6.5 & 82.4 & 11.9 & 26.4 & 3.3 & 23 \\
\hline Malmö & 1421 & 64.2 & 6.2 & 176.4 & 6.6 & 82.5 & 12.3 & 26.5 & 3.4 & 16 \\
\hline Umeả & 1344 & 57.8 & 6.9 & 177.1 & 6.4 & 82.4 & 11.5 & 26.3 & 3.2 & 30 \\
\hline
\end{tabular}

BMI - body mass index; SD - standard deviation.

- At the time of interview. 
Table A2 Age, anthropometry and frequency of special diet at recall in the European Prospective Investigation into Cancer and Nutrition (EPIC) calibration sub-populations: women

\begin{tabular}{|c|c|c|c|c|c|c|c|c|c|c|}
\hline \multirow[b]{2}{*}{ Country and centre } & \multirow[b]{2}{*}{$n$} & \multicolumn{2}{|c|}{ Age (years) ${ }^{\star}$} & \multicolumn{2}{|c|}{ Height $(\mathrm{cm})$} & \multicolumn{2}{|c|}{ Weight (kg) } & \multicolumn{2}{|c|}{ BMI $\left(\mathrm{kg} \mathrm{m}^{-2}\right)$} & \multirow[b]{2}{*}{$\%$ Special diet } \\
\hline & & Mean & SD & Mean & SD & Mean & SD & Mean & SD & \\
\hline Greece & 1374 & 57.2 & 9.9 & 156.1 & 6.3 & 70.8 & 11.8 & 29.1 & 4.9 & 25 \\
\hline Spain & 1443 & 52.9 & 8.3 & 158.6 & 5.9 & 68.1 & 10.6 & 27.1 & 4.3 & 18 \\
\hline Granada & 300 & 54.6 & 8.1 & 157.6 & 5.3 & 69.4 & 10.4 & 28.0 & 4.3 & 18 \\
\hline Murcia & 304 & 51.6 & 8.6 & 158.8 & 6.3 & 69.3 & 10.9 & 27.6 & 4.7 & 12 \\
\hline Navarra & 271 & 53.6 & 7.8 & 158.5 & 5.9 & 67.1 & 9.5 & 26.8 & 3.9 & 18 \\
\hline San Sebastian & 244 & 51.8 & 8.2 & 160.0 & 6.0 & 66.6 & 11.7 & 26.0 & 4.6 & 10 \\
\hline Asturias & 324 & 52.9 & 8.4 & 158.6 & 5.9 & 67.6 & 10.2 & 26.9 & 4.0 & 27 \\
\hline Italy & 2512 & 54.7 & 7.3 & 158.6 & 6.1 & 65.1 & 10.9 & 25.9 & 4.3 & 15 \\
\hline Ragusa & 138 & 50.6 & 8.3 & 156.1 & 5.5 & 65.0 & 11.5 & 26.7 & 4.5 & 8 \\
\hline Naples & 403 & 54.2 & 6.7 & 157.2 & 5.6 & 67.9 & 11.4 & 27.5 & 4.5 & 22 \\
\hline Florence & 785 & 55.2 & 7.0 & 160.0 & 6.1 & 65.3 & 11.0 & 25.6 & 4.2 & 15 \\
\hline Turin & 392 & 54.2 & 6.9 & 159.4 & 6.2 & 64.6 & 10.7 & 25.4 & 4.0 & 10 \\
\hline Varese & 794 & 55.3 & 7.6 & 158.0 & 5.9 & 63.8 & 10.4 & 25.6 & 4.2 & 16 \\
\hline France & 4639 & 57.0 & 6.9 & 161.4 & 5.7 & 61.1 & 9.8 & 23.5 & 3.5 & 22 \\
\hline South coast & 612 & 57.6 & 6.8 & 161.4 & 5.2 & 60.3 & 9.1 & 23.1 & 3.2 & 26 \\
\hline South & 1396 & 56.6 & 7.0 & 161.4 & 5.7 & 60.4 & 9.4 & 23.2 & 3.3 & 17 \\
\hline North-west & 622 & 56.9 & 6.7 & 160.7 & 5.5 & 60.4 & 10.0 & 23.4 & 3.7 & 29 \\
\hline North-east & 2009 & 57.1 & 7.0 & 161.7 & 5.9 & 62.2 & 10.3 & 23.8 & 3.7 & 22 \\
\hline Germany & 2150 & 51.6 & 8.6 & 163.3 & 6.3 & 68.6 & 12.6 & 25.8 & 4.7 & 18 \\
\hline Heidelberg & 1087 & 50.3 & 8.5 & 164.2 & 6.2 & 67.7 & 12.4 & 25.1 & 4.8 & 21 \\
\hline Potsdam & 1063 & 53.0 & 8.6 & 162.4 & 6.3 & 69.6 & 12.7 & 26.4 & 4.6 & 15 \\
\hline The Netherlands & 2960 & 55.1 & 8.3 & 164.8 & 6.1 & 70.4 & 12.1 & 25.9 & 4.4 & 20 \\
\hline Bilthoven & 1086 & 48.9 & 7.5 & 165.2 & 6.3 & 70.3 & 12.6 & 25.8 & 4.5 & 11 \\
\hline Utrecht & 1874 & 58.7 & 6.3 & 164.6 & 5.9 & 70.5 & 11.8 & 26.0 & 4.3 & 26 \\
\hline United Kingdom & 768 & 55.6 & 8.9 & 162.3 & 6.1 & 66.1 & 11.3 & 25.1 & 4.2 & 36 \\
\hline General population & 571 & 56.1 & 9.0 & 162.0 & 6.0 & 67.3 & 11.3 & 25.7 & 4.2 & 24 \\
\hline 'Health-conscious' & 197 & 54.1 & 8.7 & 163.3 & 6.4 & 62.6 & 10.6 & 23.5 & 3.8 & 72 \\
\hline Denmark & 1995 & 56.8 & 4.4 & 164.6 & 6.0 & 69.0 & 11.8 & 25.5 & 4.2 & 11 \\
\hline Copenhagen & 1485 & 57.1 & 4.4 & 164.7 & 6.0 & 69.3 & 11.9 & 25.6 & 4.2 & 13 \\
\hline Aarhus & 510 & 55.9 & 4.4 & 164.4 & 5.7 & 68.2 & 11.2 & 25.2 & 4.1 & 8 \\
\hline Sweden & 3285 & 58.6 & 8.4 & 163.7 & 5.8 & 69.2 & 11.5 & 25.8 & 4.2 & 28 \\
\hline Maimö & 1711 & 61.4 & 7.8 & 163.4 & 5.8 & 69.3 & 11.7 & 26.0 & 4.3 & 21 \\
\hline Umeå & 1574 & 55.6 & 8.0 & 164.0 & 5.7 & 69.2 & 11.3 & 25.7 & 4.1 & 36 \\
\hline Norway & 1798 & 49.3 & 4.3 & 166.9 & 5.6 & 67.2 & 10.5 & 24.1 & 3.6 & 16 \\
\hline South \& East & 1136 & 49.5 & 4.3 & 167.2 & 5.5 & 66.8 & 10.3 & 23.9 & 3.5 & 16 \\
\hline North \& West & 662 & 49.0 & 4.3 & 166.5 & 5.8 & 67.7 & 10.9 & 24.4 & 3.7 & 16 \\
\hline
\end{tabular}

BMI - body mass index; SD - standard deviation.

-At the time of interview. 
Table A3 Physical activity at work in the European Prospective Investigation into Cancer and Nutrition (EPIC) calibration subpopulations: men

\begin{tabular}{|c|c|c|c|c|c|c|c|c|c|c|c|c|}
\hline \multirow[b]{2}{*}{ Country and centre } & \multicolumn{2}{|c|}{ Non-worker } & \multicolumn{2}{|c|}{$\begin{array}{l}\text { Sedentary } \\
\text { occupation }\end{array}$} & \multicolumn{2}{|c|}{$\begin{array}{l}\text { Standing } \\
\text { occupation }\end{array}$} & \multicolumn{2}{|c|}{ Manual work } & \multicolumn{2}{|c|}{$\begin{array}{c}\text { (Heavy) } \\
\text { Manual work }\end{array}$} & \multicolumn{2}{|c|}{ Missing } \\
\hline & $n$ & $\%$ & $\mathrm{n}$ & $\%$ & $n$ & $\%$ & $n$ & $\%$ & $n$ & $\%$ & $n$ & $\%$ \\
\hline Greece & 545 & 41.5 & 277 & 21.1 & 200 & 15.2 & 219 & 16.7 & 23 & 1.8 & 48 & 3.7 \\
\hline Spain & 116 & 6.5 & 590 & 33.2 & 574 & 32.3 & 395 & 22.2 & 102 & 5.7 & - & - \\
\hline Granada & 13 & 6.1 & 88 & 41.1 & 70 & 32.7 & 28 & 13.1 & 15 & 7.0 & - & - \\
\hline Murcia & 17 & 7.0 & 86 & 35.4 & 83 & 34.2 & 31 & 12.8 & 26 & 10.7 & - & - \\
\hline Navarra & 26 & 5.9 & 135 & 30.4 & 146 & 32.9 & 115 & 25.9 & 22 & 5.0 & - & - \\
\hline San Sebastian & 4 & 0.8 & 169 & 34.5 & 128 & 26.1 & 173 & 35.3 & 16 & 3.3 & - & - \\
\hline Asturias & 56 & 14.5 & 112 & 29.0 & 147 & 38.1 & 48 & 12.4 & 23 & 6.0 & - & - \\
\hline Italy & 460 & 31.9 & 480 & 33.2 & 253 & 17.5 & 158 & 10.9 & 78 & 5.4 & 15 & 1.0 \\
\hline Ragusa & 22 & 13.1 & 64 & 38.1 & 40 & 23.8 & 16 & 9.5 & 24 & 14.3 & 2 & 1.2 \\
\hline Florence & 60 & 22.1 & 115 & 42.4 & 47 & 17.3 & 32 & 11.8 & 14 & 5.2 & 3 & 1.1 \\
\hline Turin & 247 & 36.5 & 209 & 30.9 & 115 & 17.0 & 70 & 10.3 & 27 & 4.0 & 9 & 1.3 \\
\hline Varese & 131 & 39.9 & 92 & 28.0 & 51 & 15.5 & 40 & 12.2 & 13 & 4.0 & 1 & 0.3 \\
\hline Germany & 773 & 34.1 & 894 & 39.4 & 464 & 20.5 & 120 & 5.3 & 15 & 0.7 & 2 & 0.1 \\
\hline Heidelberg & 278 & 26.9 & 465 & 45.0 & 227 & 22.0 & 54 & 5.2 & 9 & 0.9 & - & - \\
\hline Potsdam & 495 & 40.1 & 429 & 34.7 & 237 & 19.2 & 66 & 5.3 & 6 & 0.5 & 2 & 0.2 \\
\hline The Netherlands & 237 & 23.1 & 359 & 35.1 & 166 & 16.2 & 90 & 8.8 & 81 & 7.9 & 91 & 8.9 \\
\hline Bilthoven & 237 & 23.1 & 359 & 35.1 & 166 & 16.2 & 90 & 8.8 & 81 & 7.9 & 91 & 8.9 \\
\hline United Kingdom & 218 & 42.1 & 136 & 26.3 & 63 & 12.2 & 69 & 13.3 & 16 & 3.1 & 16 & 3.1 \\
\hline General population & 173 & 42.8 & 101 & 25.0 & 51 & 12.6 & 51 & 12.6 & 15 & 3.7 & 13 & 3.2 \\
\hline 'Health-conscious' & 45 & 39.5 & 35 & 30.7 & 12 & 10.5 & 18 & 15.8 & 1 & 0.9 & 3 & 2.6 \\
\hline Denmark & 304 & 15.8 & 820 & 42.6 & 325 & 16.9 & 352 & 18.3 & 122 & 6.3 & - & - \\
\hline Copenhagen & 217 & 16.0 & 590 & 43.5 & 223 & 16.4 & 241 & 17.8 & 85 & 6.3 & - & - \\
\hline Aarhus & 87 & 15.3 & 230 & 40.6 & 102 & 18.0 & 111 & 19.6 & 37 & 6.5 & - & - \\
\hline Sweden & 1091 & 39.5 & 625 & 22.6 & 684 & 24.7 & 297 & 10.7 & 52 & 1.9 & 16 & 0.6 \\
\hline Malmö & 752 & 52.9 & 359 & 25.3 & 207 & 14.6 & 83 & 5.8 & 19 & 1.3 & 1 & 0.1 \\
\hline Umeå & 339 & 25.2 & 266 & 19.8 & 477 & 35.5 & 214 & 15.9 & 33 & 2.5 & 15 & 1.1 \\
\hline
\end{tabular}


Table A4 Physical activity at work in the European Prospective Investigation into Cancer and Nutrition (EPIC) calibration subpopulations: women

\begin{tabular}{|c|c|c|c|c|c|c|c|c|c|c|c|c|}
\hline \multirow[b]{2}{*}{ Country and centre } & \multicolumn{2}{|c|}{ Non-worker } & \multicolumn{2}{|c|}{$\begin{array}{l}\text { Sedentary } \\
\text { occupation }\end{array}$} & \multicolumn{2}{|c|}{$\begin{array}{l}\text { Standing } \\
\text { occupation }\end{array}$} & \multicolumn{2}{|c|}{$\begin{array}{l}\text { Manual } \\
\text { work }\end{array}$} & \multicolumn{2}{|c|}{$\begin{array}{c}\text { (Heavy) } \\
\text { Manual } \\
\text { work }\end{array}$} & \multicolumn{2}{|c|}{ Missing } \\
\hline & $n$ & $\%$ & $n$ & $\%$ & $n$ & $\%$ & $n$ & $\%$ & $n$ & $\%$ & $n$ & $\%$ \\
\hline Greece & 864 & 62.9 & 213 & 15.5 & 214 & 15.6 & 76 & 5.5 & - & - & 7 & 0.5 \\
\hline Spain & 49 & 3.4 & 174 & 12.1 & 1191 & 82.5 & 25 & 1.7 & 4 & 0.3 & - & - \\
\hline Granada & 8 & 2.7 & 25 & 8.3 & 264 & $\mathbf{8 8 . 0}$ & 3 & 1.0 & - & - & - & - \\
\hline Murcia & 4 & 1.3 & 44 & 14.5 & 247 & 81.3 & 6 & 2.0 & 3 & 1.0 & - & - \\
\hline Navarra & 13 & 4.8 & 27 & 10.0 & 226 & 83.4 & 5 & 1.8 & - & - & - & - \\
\hline San Sebastian & 2 & 0.8 & 44 & 18.0 & 192 & 78.7 & 6 & 2.5 & - & - & - & - \\
\hline Asturias & 22 & 6.8 & 34 & 10.5 & 262 & 80.9 & 5 & 1.5 & 1 & 0.3 & - & - \\
\hline Italy & 1419 & 56.5 & 594 & 23.6 & 291 & 11.6 & 145 & 5.8 & 49 & 2.0 & 14 & 0.6 \\
\hline Ragusa & 67 & 48.6 & 41 & 29.7 & 24 & 17.4 & 3 & 2.2 & 3 & 2.2 & - & - \\
\hline Naples & 231 & 57.3 & 112 & 27.8 & 27 & 6.7 & 22 & 5.5 & 11 & 2.7 & - & - \\
\hline Florence & 417 & 53.1 & 209 & 26.6 & 109 & 13.9 & 35 & 4.5 & 10 & 1.3 & 5 & 0.6 \\
\hline Turin & 233 & 59.4 & 75 & 19.1 & 46 & 11.7 & 26 & 6.6 & 12 & 3.1 & - & - \\
\hline Varese & 471 & 59.3 & 157 & 19.8 & 85 & 10.7 & 59 & 7.4 & 13 & 1.6 & 9 & 1.1 \\
\hline France & 1753 & 37.8 & 706 & 15.2 & 1879 & 40.5 & 76 & 1.6 & - & - & 225 & 4.9 \\
\hline South coast & 265 & 43.3 & 77 & 12.6 & 244 & 39.9 & 6 & 1.0 & - & - & 20 & 3.3 \\
\hline South & 534 & 38.3 & 198 & 14.2 & 573 & 41.0 & 22 & 1.6 & - & - & 69 & 4.9 \\
\hline North-west & 240 & 38.6 & 85 & 13.7 & 251 & 40.4 & 12 & 1.9 & - & - & 34 & 5.5 \\
\hline North-east & 714 & 35.5 & 346 & 17.2 & 811 & 40.4 & 36 & 1.8 & - & - & 102 & 5.1 \\
\hline Germany & 843 & 39.2 & 748 & 34.8 & 498 & 23.2 & 46 & 2.1 & 3 & 0.1 & 12 & 0.6 \\
\hline Heidelberg & 388 & 35.7 & 373 & 34.3 & 280 & 25.8 & 33 & 3.0 & 2 & 0.2 & 11 & 1.0 \\
\hline Potsdam & 455 & 42.8 & 375 & 35.3 & 218 & 20.5 & 13 & 1.2 & 1 & 0.1 & 1 & 0.1 \\
\hline The Netherlands & 1495 & 50.5 & 507 & 17.1 & 458 & 15.5 & 270 & 9.1 & 143 & 4.8 & 87 & 2.9 \\
\hline Bilthoven & 506 & 46.6 & 204 & 18.8 & 173 & 15.9 & 83 & 7.6 & 34 & 3.1 & 86 & 7.9 \\
\hline Utrecht & 989 & 52.8 & 303 & 16.2 & 285 & 15.2 & 187 & 10.0 & 109 & 5.8 & 1 & 0.1 \\
\hline United Kingdom & 340 & 44.3 & 223 & 29.0 & 144 & 18.8 & 46 & 6.0 & - & - & 15 & 2.0 \\
\hline General population & 257 & 45.0 & 157 & 27.5 & 104 & 18.2 & 40 & 7.0 & - & - & 13 & 2.3 \\
\hline 'Health-conscious' & 83 & 42.1 & 66 & 33.5 & 40 & 20.3 & 6 & 3.0 & - & - & 2 & 1.0 \\
\hline Denmark & 589 & 29.5 & 680 & 34.1 & 339 & 17.0 & 363 & 18.2 & 23 & 1.2 & 1 & 0.1 \\
\hline Copenhagen & 442 & 29.8 & 530 & 35.7 & 231 & 15.6 & 259 & 17.4 & 22 & 1.5 & 1 & 0.1 \\
\hline Aarhus & 147 & 28.8 & 150 & 29.4 & 108 & 21.2 & 104 & 20.4 & 1 & 0.2 & - & - \\
\hline Sweden & 1048 & 31.9 & 791 & 24.1 & 948 & 28.9 & 398 & 12.1 & 80 & 2.4 & 20 & 0.6 \\
\hline Malmö & 755 & 44.1 & 462 & 27.0 & 406 & 23.7 & 80 & 4.7 & 2 & 0.1 & 6 & 0.4 \\
\hline Umeå & 293 & 18.6 & 329 & 20.9 & 542 & 34.4 & 318 & 20.2 & 78 & 5.0 & 14 & 0.9 \\
\hline Norway & - & - & - & - & - & - & - & - & - & - & 1798 & 100.0 \\
\hline South \& East & - & - & - & - & - & - & - & - & - & - & 1136 & 100.0 \\
\hline North \& West & - & - & - & - & - & - & - & - & - & - & 662 & 100.0 \\
\hline
\end{tabular}

